\title{
Análisis de discurso a medios de comunicación digitales en Chile respecto al cambio climático: encuadres para la construcción de las agendas pública y política
}

\author{
Julio Hasbún \\ Universidad de Chile
}

\section{Resumen}

Este estudio de caso busca conocer cómo los medios digitales representan el cambio climático en Chile, poniendo énfasis en la mitigación, adaptación y resiliencia. Se realizó un análisis de contenido a los cuatro medios digitales con mayor lectoría en Chile (2 liberales y 2 conservadores), durante el período que va desde la Segunda Comunicación Nacional de Cambio Climático (30/08/11) hasta la inauguración del Centro de Ciencia del Clima y la Resiliencia (31/10/13), con el fin de conocer los encuadres y narrativas predominantes en las noticias de cambio climático en Chile. Se obtuvo un corpus de 58 noticias nacionales, sobre el que se llevó a cabo un análisis de discurso crítico para comprender la presencia o ausencia de actores y narrativas, y así visibilizar las relaciones de poder. Los hallazgos más relevantes del análisis de contenido apuntan a: (i) bajo número de noticias de cambio climático en Chile $(14,83 \%)$ en relación a las internacionales; (ii) a que los definidores primarios del tema son los actores gubernamentales; (iii) y a la invisibilización de las personas y organizaciones ciudadanas.

Palabras clave: Cambio climático, encuadre medial, análisis de discurso, agenda pública.

Discourse analysis to digital media in Chile regarding climate change: frames for the construction of public and politics agendas

\begin{abstract}
This case study sought to understand how digital media represents climate change in Chile, with emphasis on mitigation, adaptation and resilience. A content analysys was made to four digital media with greater readership in Chile (2 liberal and 2 conservatives), since the Second National Communication on Climate Change (30/08/11) to the Centre for Climate Science and Resilience inauguration (31/10/13), to know the frames and prevailing narratives climate change news in Chile. A corpus of 58 national news was obtained, on wich a critical discourse analysis was made to understand the presence or absence of actors and narratives, and so make visible power relations. The most relevant findings of the content analysis were: (i) low number of news on climate change in Chile (14.83\%) compared to international; (ii) the primary definers of the subject were government actors; (iii) and the invisibility of people and civic organizations.
\end{abstract}

Keywords: Climate change, medial frame, discourse analysis, public agenda.

*Dirección de correspondencia [Correspondence

address]: Julio Hasbún, Universidad de Chile

E-mail: jhasbun@gmail.com 


\section{Introducción ${ }^{1}$}

La fuerza del ser humano es, hoy en día, capaz de intervenir el ecosistema del planeta acelerando la velocidad de ocurrencia de ciertos ciclos naturales (Crutzen y Stoermer, 2000). La más preocupante de dichas alteraciones es el alza vertiginosa de la temperatura, asociada a la combustión de gases de efecto invernadero ${ }^{2}$ (GEI), que al situarse en forma permanente en la atmósfera, constituyen un manto que impide la salida de la radiación solar, contribuyendo al aumento de la temperatura y humedad (IPCC, 2013).

Las proyecciones de los impactos futuros que esta situación puede causar son desalentadoras, más aún si consideramos que las condiciones geográficas de nuestro país lo sitúan en un escenario de alta vulnerabilidad económica, social y ambiental.

Es imperativo tomar todas las medidas posibles para minimizar la ocurrencia de los escenarios más potencialmente graves (IPCC, 2013). Esto requiere una enorme voluntad política que pueda destinar recursos con el objetivo de minimizar y hacer frente a las contingencias que las transformaciones podrían desencadenar (Giddens, 2010).

En Chile los riesgos del cambio climático no tienen un correlato en la opinión pública. Las temáticas medioambientales en general y el cambio climático en particular tienen baja visibilidad en la agenda. Esto ha hecho que la respuesta política haya avanzado pesadamente, y nos encontremos lejos de una política pública concreta.

La voluntad política, depende en gran medida de la tabla de prioridades que existen en la agenda pública en un momento determinado, razón por la cual el poder que poseen los medios de comunicación es fundamental, gracias a su capacidad para influenciar a la opinión pública, constructo medible gracias a encuestas de opinión periódicas (Kingdon, 1984).

Desde la interfaz entre comunicación y política, este estudio de caso busca aproximarse a comprender cómo se comunica el cambio climático en Chile, mediante un análisis de discurso a cuatro medios de prensa digital, durante el periodo 2011-2013.

Así, esta investigación busca responder dos interrogantes:

\footnotetext{
${ }^{1}$ Este trabajo ha sido auspiciado por: Beca CONICYT magíster y el proyecto CONICYT/FONDAP N 15110009

${ }^{2} \mathrm{El}$ más importante de ellos es el $\mathrm{CO} 2$, cuyo límite máximo seguro en la atmósfera ha sido fijado en 350 partes por millón. Actualmente hay 401.3 ppm. [en línea] http://co2now.org [Consulta: 13/08/14]
}

- ¿Cómo los medios digitales representan el cambio climático y la resiliencia al cambio climático en Chile?

- ¿Cuáles son las posiciones y discursos que los distintos actores, visibilizados por los medios estudiados, adoptan respecto al cambio climático en Chile?

De esta manera, el objetivo de investigación es analizar los discursos de cuatro medios de prensa digital en Chile respecto al cambio climático y la resiliencia al cambio climático.

\section{Proceso de encuadre}

El proceso de enmarcado o encuadre (framing) refiere la manera en que eventos, temas o decisiones adquieren diversos significados. En términos de saliencia, "encuadrar es seleccionar algunos aspectos de una realidad percibida y hacerlos más salientes en un texto comunicativo, de tal forma de promover una particular definición de un problema, una interpretación causal, una evaluación moral y/o recomendación de tratamiento para el objeto descrito" (Entman, 1993).

Los encuadres configuran los términos de quienes participan en el debate, afectando las preferencias de las personas, especialmente bajo condiciones de incertidumbre (Tversky y Kahnemann, 1981, citado en Dewulf, 2013). "Los encuadres pueden ser comprendidos como narrativas fuertes y genéricas que guían tanto el análisis como la acción en situaciones prácticas" (Dewulf, 2013: 322).

\section{Encuadre medial}

Un encuadre medial es una "idea organizadora central para el contenido de las noticias que provee un contexto y sugiere qué es el tema mediante el uso de la selección, énfasis, exclusión y elaboración" (Tankard, et al. 1991 citado en McCombs y Ghanem, 2003: 70). Son la perspectiva con que son narradas las noticias, generando narrativas (storytellings) que, amplificadas en el espacio público por los medios, aportan en la definición y construcción de las visiones de mundo y estilos de vida, sin desmerecer la propia capacidad de agencia e interpretación que poseen los individuos en el proceso. Los encuadres mediales son importantes por su habilidad para "definir los términos del debate sin que la audiencia lo note" (Tankard, 2003: 97). Su influencia radica en la habilidad para conectar los encuadres con aspectos emocionales que escapan del análisis consciente. 


\section{Agenda de medios y definidores pri- marios}

Baumgartner y Jones (1993) establecen que períodos de episodios con alta saliencia en los medios, estaban típicamente asociados con cambios políticos importantes y de largo plazo, de forma que es posible hablar de una retroalimentación entre la agenda de medios y la agenda política en la construcción de la agenda pública.

Hall (2000) observan las estructuras rutinarias de la producción de noticias, concluyendo que en última instancia los medios reproducen las definiciones de los poderosos, en tanto fuentes acredita$\operatorname{das}^{3}$. Este encuadre inicial provee los criterios bajo los cuales todas las contribuciones subsiguientes son consideradas como "relevantes" o "irrelevantes".

\section{Fijación de la agenda}

Los problemas surgen (obtienen "saliencia") y desaparecen de las agendas políticas y públicas, en forma independiente de su estado objetivo (Baumgartner y Jones, 1993). Problemas que no poseen soluciones disponibles o factibles, incluso si atraen la atención del público y el gobierno, es probable que no lleguen a la agenda de decisión (Kingdon, 1984). Los problemas pueden surgir en la agenda para luego desvanecerse, porque el público los encuentra "aburridos", volviéndose hacia otros temas, o bien asumiendo que han sido resueltos por el gobierno (Downs, 1972). En suma, la teoría de la fijación de la agenda investiga el devenir de distintos temas de política pública, buscando comprender por qué reciben mayor o menor atención del público y el gobierno, tratando de explicar los patrones de atención (Pralle, 2009).

Esta perspectiva teórica se basa en los siguientes supuestos:

- En los sistemas políticos democráticos coexisten tres agendas: la pública, la gubernamental, y la de decisión. La agenda pública se refiere al set de temas más salientes para los ciudadanos y votantes; la agenda gubernamental contiene los temas que son discutidos por las instituciones gubernamentales; y la agenda de decisión

\footnotetext{
${ }^{3}$ De allí la distinción entre "hechos" y "opiniones" realizada por los periodistas; los definidores primarios institucionales serían fuente de los primeros (Hall, 2000). Chomsky y Herman (2009) plantean que los medios son "disciplinados" por el gobierno, ya que necesitan autorización y concesión de éste, estando en una posición de dependencia técnica legal en "que si sus políticas se apartan con demasiada frecuencia de la orientación del establishment pueden activar esta amenaza" (40-41).
}

es el conjunto más reducido de temas sobre los que los funcionarios gubernamentales están a punto de tomar una decisión.

- Cada una de estas agendas posee una "capacidad de transporte" limitada de temas que puede manejar simultáneamente, por lo que se crea una competición entre los temas para ocupar un lugar en ellas (McCombs y Ghanem, 2003).

- No es conveniente caracterizar los temas como si estuviesen dentro o fuera de la agenda, sino ocupando puntos en un continuo en que algunos temas son más y otros menos salientes.

- Los temas con más saliencia tienen más probabilidades de entrar en la agenda de decisión de las instituciones gubernamentales, a los cuales se les entregará más recursos y esfuerzos para su resolución (Cobb y Elder, 1972).

\section{Corrientes de la Fijación de Agenda}

El modelo de "corrientes" (streams) de la fijación de agenda de Kingdon (1984) pone atención a cómo los problemas ganan saliencia en la opinión pública, avanzando así hacia la agenda de decisión. El alza o caída de los temas en la agenda, es producto de la interacción de tres corrientes o procesos políticos: los problemas, las políticas (policies) y la política (politics).

Los problemas llaman la atención de los tomadores de decisión vía: (1) indicadores, (2) eventos focalizados y (3) retroalimentación. Los indicadores revelan el alcance y severidad de los problemas. Los eventos focalizados dramáticos captan la atención del público y los tomadores de decisión. Finalmente, los tomadores de decisión aprenden de los problemas mediante la retroalimentación de los programas y políticas actuales.

En la corriente de políticas (policy) las soluciones son generadas por especialistas y expertos dentro de comunidades de políticas, las cuales están esperando ser asociadas a los problemas salientes del día. Kingdon (1984) plantea que las soluciones propuestas deben pasar la prueba de factibilidad y congruencia con los valores imperantes para ser seleccionadas. Aquellos problemas que no tengan soluciones asociadas encontrarán gran dificultad para avanzar hacia la agenda gubernamental y de decisiones. El público es menos dado a preocuparse acerca de los problemas cuando siente que no hay nada que hacer sobre ellos (Abbasi, 2006).

La oportunidad política del modelo de corrientes pone el foco en tres factores políticos clave que afectan la agenda: (1) el ánimo nacional, (2) las 
fuerzas políticas organizadas, y (3) y los cambios (turnover) administrativos o legislativos.

Los tomadores de decisión "toman la temperatura" al ánimo nacional a través de encuestas de opinión pública, prestando más o menos atención a algunos problemas o soluciones que a otros (Pralle, 2009). Los grupos de interés pueden contribuir a que los tomadores de decisión comprendan las preferencias del público (o al menos las preferencias de un segmento de éste), y cómo varias soluciones afectarán a grupos objetivos (influenciando las percepciones de factibilidad de los tomadores de decisión). El balance entre los grupos de interés que apoyan y se oponen a una política da forma a las agendas de los tomadores de decisión y la selección de alternativas (Kingdon, 1984). Los cambios electorales usualmente conllevan cambios importantes en la agenda, en tanto la nueva administración presiona por llevar adelante sus temas, elevando el estatus de ciertos problemas y soluciones.

La posibilidad de que cualquier tema gane prominencia en la agenda es incrementada significativamente cuando la corriente de problemas, de políticas y de política actúan juntas. Esa ventana de oportunidades abierta es el resultado de actividades en la corriente de política o porque un problema está presionando con fuerza. Existen ventanas de oportunidades predecibles y no predecibles, y los emprendedores de políticas deben estar listos para actuar en el momento justo, pues las ventanas raramente permanecen abiertas por mucho tiempo.

\section{Convergencia entre proceso de enmar- cado y la fijación de agenda}

McCombs y Ghanem (2003) establecen la convergencia empírica entre ambas tradiciones teóricas, señalando que "encuadrar es construir una agenda con un número restringido de atributos relacionados temáticamente en orden a crear un cuadro coherente de un objeto particular". La construcción de la agenda de atributos está asociada a los problemas, causas y soluciones específicos, así como los pros y contras racionales con que es presentado el tema (McCombs y Ghanem, 2003).

\section{Metodología}

Para conocer la diversidad de tendencias presentes en el discurso público, se han seleccionado cuatro medios de prensa digital, tanto por su perfil político editorial (liberal-centro izquierda/conservador-derecha ${ }^{4}$ ) como por su nivel de lectoría. Se eligieron de esta manera los medios emol.com (+ leído) y latercera.com (- leído), diarios con una tendencia conservadora y de derecha. Por otra parte se eligieron los medios elmostrador.cl (+ leído) y lanación.cl (- leído), con una tendencia liberal y de centro izquierda ${ }^{5}$. Con el fin de obtener una mirada transversal (diacrónica) a las noticias de cambio climático en Chile, se realizó una revisión a estos cuatro medios de prensa digital, tomando dos hitos como referencia: desde el 30 de agosto de 2011, fecha de presentación de la Segunda Comunicación Nacional de Cambio Climático en Chile, hasta el 31 de Octubre de 2013, mes de inauguración del Centro de Ciencia del Clima y la Resiliencia (CR2).

Se siguieron dos criterios de selección: a) noticias nacionales, incluyendo noticias de chilenos en el extranjero hablando del país, o de extranjeros hablando de Chile; y b) noticias que en su título, bajada, primer y segundo párrafo (leads) mencionen alguno de los siguientes conceptos: (i) cambio climático, (ii), calentamiento global, (iii) cambio global, y (iv) efecto invernadero.

Posteriormente, se aplicó un análisis de contenido a la muestra obtenida. La característica relevante del análisis de contenido para los fines de esta investigación es que los textos poseen significados (contenidos), relativos a contextos, discursos y propósitos particulares: "los mensajes siempre ocurren en situaciones particulares, los textos son leídos con intenciones particulares y la data es informativa en relación a problemas particulares" (Krippendorf 2004: 24). En el caso de este estudio de caso, el contexto que informa el rango de posibilidades de interpretación de los textos analizados (prensa escrita digital) es la agenda pública o sistémica, la cual "está integrada por todas las cuestiones que los miembros de una comunidad política perciben comúnmente como merecedoras de la atención pública" (Cobb y Elder, 1972).

\footnotetext{
${ }^{4}$ Nos referimos a su tendencia histórica, siendo conservadores aquellos medios que defienden el statu quo, por ejemplo, mediante el mantenimiento de un sistema de mercado neoliberal expresado en el Consenso de Washington, implantado bajo el régimen autoritario del General Augusto Pinochet. Los liberales propugnan reformas a este sistema, entregándole mayor capacidad de supervisión y sanción al Estado.

${ }^{5}$ Estos indicadores fueron tomados de la encuesta nacional realizada por la Universidad Diego Portales y la agencia Feedback (2011). Es probable que durante los últimos tres años estos números hayan variado.
} 


\section{Categorización}

Se realizó una categorización a priori para facilitar la búsqueda de patrones en la data obtenida, sin perjuicio de prestar atención a categorías emergentes no consideradas previamente. Las categorías a revisar se corresponden con la estructura o árbol de nodos que provee Nvivo 10 para generar la codificación.

A continuación se presenta el árbol de codificación, donde se pueden apreciar los temas (nodos) y subtemas (subnodos) utilizados en la codificación, así como sus definiciones (Tabla 1).

Se realizó una codificación primaria, con el fin de probar la capacidad heurística de la categorización previa, y así ajustar las categorías emergentes y las peculiaridades del material.

Por último, se utilizó un análisis crítico de discurso (Van Dijk, 1999). En la lógica crítica, los discursos son históricamente producidos e interpretados por estructuras de dominio, estructuras que son legitimadas por las ideologías ${ }^{7}$ de los grupos poderosos. La dinámica de dominio lleva a que ciertas estructuras se estabilicen en convenciones y sean naturalizadas por los miembros de una sociedad, tomándose como "dadas" (Wodak, 2001).

Se analizaron los encuadres utilizados para presentar el cambio climático, los que se constituyen como narrativas que poseen grados mayores o menores de institucionalización. Cuando estas narrativas expresan posiciones conflictivas producto del enfrentamiento entre quienes aspiran a cambiar las estructuras societales y aquellos que tienen intereses para mantenerlas, toman la forma de discursos, en tanto dispositivos de control para el acceso diferencial a decidir respecto al uso de ciertos recursos (económicos, políticos).

\section{Resultados}

Destaca la baja cantidad de noticias nacionales de cambio climático en la muestra estudiada $(\mathrm{n}=58 / 14,83 \%)$, con un alto predominio de las internacionales $(333 / 85,16 \%)$. Si tomamos el conjunto de los cuatro medios estudiados, encontramos con que se publica en promedio una noticia internacional de cambio climático cada 2,34 días. En cambio, tenemos una noticia nacional de cambio climático cada 12,78 días, en promedio. El medio más activo en el periodo referente al tema de

\footnotetext{
${ }^{7} \mathrm{El}$ concepto ideología remite a las formas y procesos sociales dentro de las cuales las formas simbólicas circulan en el mundo social (Thompson 1990, en: Wodak, 2001:10).
}

análisis es emol.com (25), seguido por latercera.com (22), y luego lanacion.cl (11). El diario electrónico elmostrador.cl no presenta noticias de cambio climático en Chile, ya que da preponderancia a las columnas de opinión y a la reproducción de noticias de agencias internacionales (BBC, entre otras), de lo cual se puede inferir que no cuenta con periodistas especializados en medioambiente.

En relación a las agencias de noticias implicadas en la muestra, dominan Emol y La Tercera, siendo probable que ambas cuenten con equipos periodísticos especializados en temas medioambientales

Los actores con mayor presencia son los políticos, seguidos por los científicos y expertos, y por los organismos internacionales. Más atrás están los empresarios, siendo notable la ausencia de actores ciudadanos (Tabla 2).

Los actores con mayor número de menciones son el Ministro o Subsecretario de Agricultura (6), y el Ministro o Subsecretario de Medio Ambiente (6), seguidos por el Presidente de la República (4).

La Tabla 3 presenta una panorámica de cada nodo y sub nodo analizado, destacando como encuadres preponderantes de la muestra: "ciencia válida", que no cuestiona la existencia del cambio climático y "adaptación al cambio climático", seguidos más atrás por el encuadre de "mitigación del cambio climático". Es relevante notar el bajo nivel de menciones recibidos por "ciencia no-válida", "resiliencia al cambio climático", y la inexistencia de menciones para el sub nodo "reducción absoluta de emisiones".

\section{Existencia del Fenómeno}

En este acápite se presentan los resultados del tema "existencia del fenómeno", que busca conocer la forma en que los medios electrónicos estudiados cubren la ciencia del cambio climático, respecto a la problemática denominada "escepticismo al cambio climático". Bajo este rótulo confluyen al menos tres encuadres: el de incertidumbre, controversia, y el escepticismo en sí (Antilla, 2005; Capstick y Pidgeon, 2014; Engels et al., 2013; Whitmarsh, 2011). Este tema a su vez ha sido subdividido en tres encuadres: (i) ciencia válida, (ii) ciencia incierta, y (iii) ciencia controversial, división que hemos adaptado de los encuadres hallados por Antilla (2005) en su investigación acerca de la cobertura de la ciencia del cambio climático en diarios estadounidenses. 
Tabla 1: Árbol de codificación

\begin{tabular}{|c|c|}
\hline Nodo & Sub nodo \\
\hline $\begin{array}{l}\text { Existencia del Fenómeno } \\
\text { (Antilla, 2005) }\end{array}$ & $\begin{array}{l}\text { Ciencia válida: La existencia del cambio climático es un hecho científico fuera } \\
\text { de discusión } \\
\text { Ciencia no-válida }: \text { La existencia del cambio climático no es un hecho científi- } \\
\text { co, por tanto no está exento de discusión }\end{array}$ \\
\hline $\begin{array}{l}\text { Atribución de Causalidad } \\
\text { (Boykoff y Boykoff, 2004) }\end{array}$ & $\begin{array}{l}\text { Cambio climático antropogénico: Se presenta a la acción humana como } \\
\text { responsable principal del cambio climático } \\
\text { Escepticismo hacia la contribución antropogénica: El cambio climático } \\
\text { responde a causas naturales, y no humanas } \\
\text { Reportes balanceados: En búsqueda de imparcialidad informativa se pre- } \\
\text { sentan ambas posiciones en la noticia }\end{array}$ \\
\hline $\begin{array}{l}\text { Mitigación del CC } \\
\text { (Fransen Taryn, 2011) }\end{array}$ & $\begin{array}{l}\text { Reducción de intensidad de emisiones: Se presentan medidas y/o acciones } \\
\text { orientadas a la reducción en la intensidad de emisiones de GEI } \\
\text { Reducción absoluta de emisiones: Se presentan medidas y/o acciones ten- } \\
\text { dientes a la reducción absoluta de emisiones } \\
\text { Metas de carbono neutralidad: Se presentan medidas y/o acciones de car- } \\
\text { bono neutralidad, es decir, a compensar las emisiones de CO2 con su equivalente } \\
\text { en capacidad de absorción } \\
\text { Otras acciones de mitigación: Se presentan otras medidas y/o acciones de } \\
\text { mitigación, distintas a las anteriores }\end{array}$ \\
\hline $\begin{array}{l}\text { Adaptación al CC } \\
\text { (Juhola et al., 2011) }\end{array}$ & $\begin{array}{l}\text { Vulnerabilidad: La adaptación se presenta como respuesta a la vulnerabilidad } \\
\text { percibida a los impactos del cambio climático } \\
\text { Planificación: La adaptación se presenta integrando procesos de planificación } \\
\text { en búsqueda de soluciones a los impactos del cambio climático } \\
\text { Riesgo económico: La adaptación al cambio climático es presentada como } \\
\text { costos y riesgos económicos, presentes y futuros } \\
\text { Medidas existentes: La adaptación es presentada como medidas existentes, } \\
\text { y contrariamente a la planificación, se ocupa del cambio climático actual, no } \\
\text { del proyectado }\end{array}$ \\
\hline Resiliencia al CC & Se menciona la resiliencia al cambio climático \\
\hline $\begin{array}{l}\text { Esperar y Observar (Al- } \\
\text { dunce, 2013) }\end{array}$ & $\begin{array}{l}\text { Se sugiere esperar por más evidencia o información científica antes de tomar } \\
\text { medidas y/o acciones frente al cambio climático }\end{array}$ \\
\hline
\end{tabular}


Tabla 2: Tipo de actores por medio de prensa

\begin{tabular}{|l|l|l|l|l|}
\hline Actor Medio & EMOL & La Tercera & La Nación & Total Actor \\
\hline Politicos & 13 & 7 & 5 & 25 \\
\hline Empresa & 4 & 1 & 1 & 6 \\
\hline Organismos Intemacionales & 7 & 5 & 1 & 13 \\
\hline Científicos y Expertos & 4 & 12 & 4 & 20 \\
\hline Otros & 1 & 0 & 0 & 1 \\
\hline Total Medio & 29 & 25 & 11 & 65 \\
\hline
\end{tabular}

Fuente: elaboración propia. $\mathrm{N}=\mathbf{5 8}$ Noticias.

Tabla 3: Número de Noticias por Nodo y Sub Nodo

\begin{tabular}{|l|l|}
\hline Nodo & Sub Nodo \\
\hline Existencia de Fenómeno (N=57) & Ciencia válida $(\mathrm{N}=54)$ \\
\cline { 2 - 2 } & Ciencia no-válida (N=3) \\
\hline Atribución de Causalidad (N=7) & Cambio climático antropogénico (N=3) \\
\cline { 2 - 2 } & Escepticismo hacia la contribución antropogénica (N=3) \\
\cline { 2 - 2 } & Reportes balanceados (N=1) \\
\hline \multirow{4}{*}{ Mitigación del CC (N=28) } & Reducción de intensidad de emisiones (N=11) \\
\cline { 2 - 2 } & Reducción absoluta de emisiones $(\mathrm{N}=0)$ \\
\cline { 2 - 2 } & Metas de carbono neutralidad $(\mathrm{N}=5)$ \\
\cline { 2 - 2 } & Otras acciones de mitigación $(\mathrm{N}=12)$ \\
\hline Adaptación al CC $(\mathrm{N}=29)$ & Vulnerabilidad $(\mathrm{N}=15)$ \\
\cline { 2 - 2 } & Planificación $(\mathrm{N}=20)$ \\
\cline { 2 - 2 } & Riesgo económico $(\mathrm{N}=15)$ \\
\cline { 2 - 2 } & Medidas existente $(\mathrm{N}=8)$ \\
\hline Resiliencia al CC $(\mathrm{N}=3)$ & Resiliencia al $\mathrm{CC}(\mathrm{N}=3)$ \\
\hline Esperar y Observar $(\mathrm{N}=5)$ & Esperar y Observar $(\mathrm{N}=5)$ \\
\hline
\end{tabular}

Fuente: elaboración propia. $\mathrm{N}=58$ Noticias.

\section{Ciencia Válida}

En este encuadre no se discute la existencia del cambio climático: es un hecho científico que no reviste mayor análisis (Antilla, 2005). Gran parte de los medios digitales analizados presentan las noticias desde "ciencia válida" (85\%), tanto de manera explícita como implícita.

$\mathrm{Al}$ observar la Tabla 4 se aprecia que en esta narrativa predominan los actores políticos (23 noticias) sobre los científicos (17 noticias). Más atrás encontramos tanto a empresarios y miembros del tercer sector, ambos con 6 noticias. Destaca la aparición de miembros del tercer sector, y la ausencia de organizaciones ciudadanas.

\section{Ciencia No-Válida}

El encuadre "ciencia incierta" y "ciencia controversial" comparten una misma noticia del medio La Tercera, razón por la cual los hemos agrupado dentro de la categoría "ciencia no-valida".
En el encuadre ciencia incierta, la noticia se orienta a enfatizar la incertidumbre existente acerca de la existencia del cambio climático. Por otra parte, "ciencia controversial" pone el acento en aspectos polémicos o en debate de la ciencia del cambio climático, específicamente en relación a la existencia del fenómeno. En este encuadre encontramos solo a actores científicos (Tabla 5).

\section{Discusión}

Antilla (2005) estudió la forma en que se presentaban 32 artículos científicos de cambio climático en Estados Unidos, encontrando que un tercio del total estaban construidos desde el encuadre "cienciano válida". La autora plantea como hipótesis que este número de encuadres de "ciencia no-válida" $(11 / 32)$ "era suficientemente prominente para tener un efecto importante de confusión entre los lectores" (Antilla, 2005:44). Este caso difiere del caso chileno, en donde solo se encontró una noticia con el encuadre "ciencia no-válida", es decir que el cambio climático es construido en los medios como un hecho científico fuera de discusión. 
Tabla 4: Ciencia Valida

\begin{tabular}{|l|l|}
\hline Actores & Ejemplos \\
\hline $\begin{array}{l}\text { Políticos } \\
(\mathrm{N}=23)\end{array}$ & $\begin{array}{l}\text { "El Presidente señaló que queda mucho por hacer para proteger mejor nuestros bosques y nuestra naturaleza, } \\
\text { no sólo frente a fenómenos como el cambio climático (...)" (EM120203). } \\
\text { "En un contexto de calentamiento global, de estrés hídrico y de total despenalización de la violación de nuestro } \\
\text { medioambiente (...) dijo Enríquez-Ominami" (EM130929). }\end{array}$ \\
\hline $\begin{array}{l}\text { Científicos } \\
(\mathrm{N}=17)\end{array}$ & $\begin{array}{l}\text { "El cambio climático es uno de los mayores desafios de nuestro siglo, y el gobiemo británico se ha } \\
\text { comprometido con el crecimiento y las bajas emisiones de carbono en la región" (130125.2). } \\
\text { "El área del Pacifico Sur es un gran ejemplo del cambio climático, es inaceptable que los países no tengan } \\
\text { registros de sus embarcaciones mercantes" (LAN121115). }\end{array}$ \\
\hline $\begin{array}{l}\text { Empresarios } \\
(\mathrm{N}=6)\end{array}$ & $\begin{array}{l}\text { "(...) el problema principal del medio ambiente a nivel mundial, es el calentamiento global (...)" (EM120113). } \\
\text { "El cambio climático es un problema real y los análisis económicos señalan que se debe actuar con urgencia si } \\
\text { no se quiere provocar efectos sociales dificilmente soportables a futuro" (LAN111114). }\end{array}$ \\
\hline $\begin{array}{l}\text { Tercer Sector } \\
(\mathrm{N}=6)\end{array}$ & $\begin{array}{l}\text { "La Red Nacional de Radiación Ultravioleta de la Corporación Nacional del Cáncer (CONAC) (...) dijo que } \\
\text { ello podría ser producto del cambio climático" (LAN121211). } \\
\text { "Al mismo tiempo hay una aproximación a la cuestión del calentamiento global", explicó Azevedo, profesora } \\
\text { de arte de la Universidad de Sao Paulo" (LT120822). }\end{array}$ \\
\hline
\end{tabular}

\section{Fuente: Elaboración propia}

Tabla 5: Ciencia No-Válida

\begin{tabular}{|l|l|}
\hline Sub Nodos & Ejemplos \\
\hline $\begin{array}{l}\text { Ciencia } \\
\text { Controversial } \\
(\mathrm{N}=2)\end{array}$ & $\begin{array}{l}\text { "La astrónoma de la U. de Chile, María Teresa Ruiz, generó diversas reacciones al cuestionar en una } \\
\text { entrevista con La Tercera el apego a la ciencia de las alarmas por el cambio climático y la noción de que el } \\
\text { hombre puede revertirlo". (LT130407) } \\
\text { "Seguir creyendo en el calentamiento global es seguir alimentando una industria de US\$ 6.000 millones", } \\
\text { dice Art Robinson, académico del Instituto de Ciencia y Medicina de Oregón, refiriéndose a la cantidad de } \\
\text { "contribuciones que hace la gente a las causas ambientalistas, promovidas por gente que siempre tiene cómo } \\
\text { hacer que el público le tema a algo". (LT130407) }\end{array}$ \\
\hline $\begin{array}{l}\text { Ciencia Incierta } \\
(\mathrm{N}=1)\end{array}$ & "Simplemente no hay evidencia creible de que el calentamiento es nocivo (...)".(LT130407) \\
\hline
\end{tabular}

Fuente: Elaboración propia

La presencia del encuadre "ciencia no-valida" en el caso estadounidense se asocia a poderes que buscan distraer tanto al público como a los tomadores de decisión, especialmente por parte de corporaciones productoras de petróleo (Antilla, 2005; Moser 2010). En Chile no existirían grupos de presión interesados en legitimar la utilización de combustibles fósiles, y, en cambio, sí encontramos a representantes de empresas generadoras de energía hidroeléctrica destacando las bondades de su industria para con el medioambiente; o bien responsabilizando al cambio climático de ciertos impactos, para así defender sus operaciones, como la realizada por Barrick Gold Corporation ante la Corte de Apelaciones de Copiapó (2013).

El "ataque" protagonizado por la astrónoma Dra. María Teresa Ruiz a la ciencia del cambio climático tuvo gran impacto medial ${ }^{8}$, el cual fue rechazado públicamente por científicos del área ${ }^{9}$. La existen-

\begin{tabular}{l}
\hline${ }^{8}$ LT130407; Revista \\
http://www.quepasa.cl/articulo/3_5234_9.html; \\
Diario electrónico Pl Pasa, \\
http://eldesconcierto.cl/cambio-climatico-el-desafio-- \\
mayor/; Tolerancia Cero, Chilevisión, entre otros medios. \\
${ }^{9}$ Carta al Editor de Tolerancia Cero de parte de expertos \\
del Centro de Ciencia del Clima y la Resiliencia (CR2), y
\end{tabular}

cia del cambio climático es avalada tanto por la política como por la ciencia en Chile. Podría hipotetizarse a partir de allí la causa de sospecha y suspicacia por parte de otras áreas del quehacer científico: no verían con buenos ojos la gran cantidad de atención y recursos que le brinda la política al fenómeno. Recordemos que Chile gasta un 0,42\% de su PIB en investigación y desarrollo, muy por debajo del $2 \%$ que en promedio destinan los países OCDE; sin embargo, el país es líder en productividad de investigación científica en Latinoamérica, con el mayor número de publicaciones científicas por habitante, por sobre Argentina, Brasil y México. Así, es posible postular la existencia de incentivos que ejercen un efecto de canibalización en el "mercado" del mundo científico chileno: la subida de las "ventas" en una industria del conocimiento, implicaría la caída en otras, en la percepción de los involucrados.

A diferencia de lo que sucede en Chile, en países desarrollados el escepticismo al cambio climático es un tema central, por cuanto la transición hacia economías bajas en carbono está ligada a la

del Centro de Cambio Global de la Pontificia Universidad Católica de Chile. 
participación política y las preferencias energéticas (Engels et al., 2013). Un elemento que en Chile podría desencadenar la triada escepticismo al cambio climático-participación políticapreferencias energéticas, es la declinación del mercado laboral, especialmente asociado al discurso del aumento de los costos de la energía para la gran industria de la minería de cobre. Es lo que afirman Scruggs y Benegal (2012) para el caso de Estados Unidos, donde en un estudio longitudinal (19742010) muestra una asociación negativa entre la salud de la economía (empleo) y la preocupación ambiental. Desde esta perspectiva sería posible que a futuro en Chile existiesen niveles significativos de escepticismo al cambio climático, dependiendo del nivel de empleo. Esta asociación estaría dentro del polo inmediato/mediato en que se inserta el cambio climático, al momento de competir por atención frente a problemas que afectan directamente la vida cotidiana de las personas, al menos desde la perspectiva de sus valoraciones y percepciones.

Además, la emergencia futura de escepticismo al cambio climático en Chile podría estar asociada con el bajo nivel de conocimiento de parte de las audiencias. Como plantea Whitmarsh (2011), las personas que se sienten más informadas muestran menos disposición a ser escépticos frente al cambio climático. Whitmarsh (2011) sostiene que la percepción de alarmismo en las noticias tiende a generar dudas en las audiencias, pero que la correlación es más fuerte entre las visiones políticas y ambientales previas y el ser escéptico o no al cambio climático (Whitmarsh, 2011; Poortinga et al., 2011; Capstick y Pidgeon, 2014).

En países en desarrollo la presencia de valores post-materialistas, como la protección del medio ambiente, sólo estaría asociada a la pequeña fracción de la población que ha alcanzado niveles de bienestar considerables, tal como halló Inglehart (1990) en sociedades industriales avanzadas; para la gran mayoría, en cambio, las fluctuaciones de los ciclos económicos y las consecuencias derivadas para la economía familiar, son el fermento necesario para gatillar una baja adhesión al cuidado ambiental, y en particular el escepticismo frente al cambio climático (Poortinga et al., 2011). Los datos actuales desestiman la tesis de Inglehart (1990), al mostrar que las personas de los países en desarrollo tienen mayor disposición a actuar y pagar que las de países desarrollados (Kim y Wolinsky-Nahmias, 2014).

En consideración al escepticismo, también es relevante considerar la relevancia y efectividad de las medidas planteadas para responder al cambio climático. Para el caso chileno, y ante la ausencia del lobby petrolero, es probable que sea relevante poner atención a este tipo de escepticismo, sobre todo en grupos de adolescentes y jóvenes que no están interesados en los procesos políticos y colectivos, como aquellos que no estudian ni trabajan (NINI), que sumaban en Chile al 2006 a 679.797 jóvenes entre 15 años y 29 años (CASEN 2006). Estos jóvenes están expuestos a una gran vulnerabilidad potencial, al estar marginados dualmente, dando cuenta de dinámicas estructurales de exclusión, que se van sosteniendo en el tiempo (UNFPACEPAL-ECLAC, 2001:74). Es posible hipotetizar que estos grupos de jóvenes son más receptivos al escepticismo en general, y por tanto más resistentes a información acerca de acciones para adoptar en la vida cotidiana.

Es importante mencionar también la gran cantidad de reuniones internacionales en que participa el gobierno de Chile, lo cual lo posiciona como un tema de moda en los círculos internacionales de la política, del que nadie quiere quedarse abajo. Este encuadre de relaciones internacionales ha sido documentado por Gordon et al. (2010) para el caso de México.

En este acápite hemos constatado que aun cuando los encuadres presentados por los medios analizados no presentan dudas respecto a la ciencia del cambio climático, las condiciones sociales, políticas y económicas de nuestro país son potencialmente favorables al escepticismo al cambio climático, gatilladas por dos fenómenos que pueden retroalimentarse: (i) que la economía entre en un ciclo contractivo $^{10}$, y (ii) que la generación de jóvenes NINI dé paso a adultos con escasa vinculación al mercado laboral.

\section{Atribución de Causalidad}

En este acápite se presentan los resultados del tema "atribución de causalidad", que busca conocer la forma en que los medios electrónicos estudiados cubren la cuestión acerca de las causas del cambio climático (naturales, artificiales), eje que estructura la discusión científica, política y económica internacional, al separar las posiciones entre quienes sostienen que el ser humano es el principal responsable del fenómeno, y aquellos que postulan que las raíces del cambio climático deben ser buscadas en

\footnotetext{
${ }^{10}$ Chile, como economía extractiva productora de commodities, depende del precio internacional de estos últimos para generar inversión pública y privada. Hoy se habla del "fin del superciclo de las materias primas" (2003-2012), lo que hará descender los precios en los años venideros. [en línea] http://www.elmostrador.cl/negocios/2014/07/17/algomas-para-preocupar-a-codelco-goldman-sachspronostica-caida-de-precios-de-materias-primasconforme-super-ciclo-llega-a-su-fin/ $17 / 07 / 2014]$
} 
el propio devenir de los ciclos naturales. Este nodo a su vez, ha sido subdividido en tres encuadres: (i) Cambio Climático Antropogénico, (ii) Escepticismo hacia la Contribución Antropogénica, y (iii) Reportes Balanceados, división que hemos adaptado de las distinciones realizadas por Boykoff y Boykoff (2004).

En la revisión de prensa digital realizada se encontraron sólo 7 noticias (12\%) que presentaban en forma explícita alguno de estos encuadres, por lo que la atribución de causalidad del cambio climático no constituye un tema significativo. Este número difiere en gran medida en relación con el nodo Existencia del Fenómeno, dado que dicha selección tomó en cuenta las noticias que en forma implícita asumían la existencia del cambio climático; por el contrario, en esta ocasión, dado que se trata de una distinción más precisa, sólo fueron considerados aquellas noticias que en forma explícita hacían mención a alguna de las narrativas que componen este nodo.

\section{Cambio Climático Antropogénico}

Este encuadre presenta al cambio climático como un fenómeno atribuible a la acción humana, aproximándose así a lo establecido por el Quinto Reporte del Panel Intergubernamental de Cambio Climático (IPCC, 2013), respecto a los cambios en las concentraciones de gases de efecto invernadero (GEI) en los últimos 60 años, que con un $95 \%$ de confianza serían causados por la quema de combustibles fósiles.

Sólo en tres noticias de la muestra emerge este encuadre en forma explícita, todas asociadas a equipos científicos del país, y publicadas por el medio digital La Tercera (Tabla 6).

\section{Escepticismo hacia la Contribución Antro- pogénica}

Este encuadre cuestiona la contribución antropogénica al cambio climático, otorgándole mayor probabilidad a causas naturales.

Sólo tres noticias de la muestra presentan este encuadre en forma explícita, teniendo como actores: un político, un empresario y dos científicos internacionales (Tabla 7).

\section{Reportes Balanceados}

Este encuadre presenta "ambos lados" de la noticia en búsqueda de imparcialidad informativa, es decir, presenta tanto la posición de aquellos que sostienen que el cambio climático responde a fluctuaciones naturales como aquellos que responsabilizan a la actividad humana.

Encontramos sólo una noticia que responde a la categoría, en el diario electrónico La Tercera (Tabla 8).

\section{Discusión}

Los resultados obtenidos contrastan con los de Maxwell T. Boykoff y Boykoff (2004), quien al examinar la prensa de prestigio estadounidense (New York Times, Washington Post, Los Angeles Times, Wall Street Journal) mostraba que dominaba el reporte balanceado por sobre los demás encuadres, lo cual responde a la utilización de una norma de ética profesional del periodismo que en Chile no se encuentra establecida en el Código de Ética del Colegio de Periodistas ${ }^{11}$, ni tampoco en la praxis profesional. Este sesgo actúa sobre-representando las posiciones de los escépticos, minoritaria en la comunidad científica del área (3\%).

El encuadre "cambio climático antropogénico" es sustentado en las noticias contabilizadas por tres científicos nacionales, en cambio, el de "escepticismo al cambio climático antropogénico" es presentada por dos científicos internacionales, una consultora de la industria eléctrica y un político nacional. Con esta información es posible hipotetizar que: (i) existe un nivel importante de consenso científico en Chile respecto a la causal antropogénica del cambio climático, o bien, (ii) los científicos escépticos al cambio climático en Chile no presentan sus dudas en público, siendo la excepción a esto, con la salvedad de que proviene de otro campo disciplinario, el caso de la Dra. María Teresa Ruiz.

El bajo número de menciones que tienen estas narrativas dentro de la muestra estudiada permite inferir que el público no percibiría como tema relevante la causalidad del cambio climático. Esto sería consistente con la Encuesta Gallup (20072008), que para el caso chileno, encuentra que un $75 \%$ de la población sostiene que el cambio climático es causado por la actividad humana, y un número similar $(73 \%)$ reporta que posee conocimiento acerca del tema.

Rahmstorf (2004) distingue tres tipos de escepticismo al cambio climático: (a) "escépticos de tendencia", que corresponden a aquellos que dudan de

\footnotetext{
${ }^{11}$ Código de Ética aprobado en el Consejo Plenario Nacional del 13 de Diciembre de 2008. [en línea] http://www.colegiodeperiodistas.cl/web/index.php/etica [Consulta: 8/06/2014]
} 
Tabla 6: Cambio Climático Antropogénico

\begin{tabular}{|l|l|}
\hline Actores & Ejemplos \\
\hline $\begin{array}{l}\text { Centro de Estudios } \\
(\mathrm{N}=1)\end{array}$ & $\begin{array}{l}\text { "En sus expediciones, el CECs ha detectado, a través del análisis del monóxido de carbono atrapado } \\
\text { en el hielo, que las concentraciones hoy exceden la variación natural que viene presentándose durante } \\
\text { las últimas decenas de miles de años. En otras palabras, el fenómeno que vemos hoy no sería de } \\
\text { origen natural". (LT130202) }\end{array}$ \\
\hline $\begin{array}{l}\text { Representante de Centro "Según Gallardo, el último reporte del Intergovernmental Panel on Climate Change (IPCC), revela } \\
\text { Científico } \\
(\mathrm{N}=2)\end{array}$ & $\begin{array}{l}\text { que existe un 95\% de evidencia de que el ser humano es el principal responsable del cambio climático } \\
\text { (...)". (LT131009) }\end{array}$ \\
\hline $\begin{array}{l}\text { Información periodística } \\
\text { en base a IPCC }\end{array}$ & $\begin{array}{l}\text { "La evidencia cientifica más reciente respalda estos relatos de primera mano, al punto que pocos } \\
\text { dudan a estas alturas de que hemos comenzado a vivir los efectos del calentamiento global y que la } \\
\text { (N=1) }\end{array}$
\end{tabular}

Fuente: Elaboración propia

Tabla 7: Escepticismo a frente a la Contribución Antropogénica

\begin{tabular}{|c|c|}
\hline Actores & jemplos \\
\hline $\begin{array}{l}\text { Político. Senador } \begin{array}{r}\text { Juan } \\
\text { Antonio Coloma }\end{array}(\mathrm{N}=2)\end{array}$ & $\begin{array}{l}\text { "Esto ocurre en Chile, así como las sequias, las inundaciones y desbordes. Lo que pasa es que el } \\
\text { cambio climático llegó para instalarse y es parte de los fenómenos naturales que se han dado en el } \\
\text { país y el mundo en el último tiempo" (EM131012, LAN131012) }\end{array}$ \\
\hline $\begin{array}{l}\text { Empresaria María Isabel } \\
\text { González, Gerente General } \\
\text { de la Consultora Eléctrica } \\
(\mathrm{N}=1)\end{array}$ & $\begin{array}{l}\text { do el calentamiento global, en Chile } \\
\text { cas para generar energía eléctrica". }\end{array}$ \\
\hline $\begin{array}{l}\text { Cientifico. Richard Lindz } \\
\text { MIT } \quad(\mathrm{N}=1)\end{array}$ & $\begin{array}{l}\mathrm{Cl} \\
\mathrm{Ca}\end{array}$ \\
\hline $\begin{array}{l}\text { Cientifico. Art Robinson, } \\
\text { Instituto de Ciencia y } \\
\text { Medicina de Oregon, Petition } \\
\text { Project } \quad(\mathrm{N}=1) \\
\end{array}$ & $\begin{array}{l}\text { "Seguir creyendo en el calentamiento global es seguir alimentando un } \\
\text { millones", (..) refiriéndose a la cantidad de "contribuciones que ha } \\
\text { ambientalistas, promovidas por gente que siempre tiene cómo hacer que } \\
\text { (LT130407) }\end{array}$ \\
\hline
\end{tabular}

Fuente: Elaboración propia

la existencia de cambio climático, abordados en el nodo anterior; (b) "escépticos de atribución", es decir, aquellos que dudan que la actividad humana sea responsable por las tendencias del clima observadas, encuadre analizado en este nodo; y finalmente (c) "escépticos de impacto", que dudan de que los efectos sean más negativos que positivos, o bien que los impactos negativos serán menores a lo señalado.

Para el caso de Inglaterra, ? encuentran evidencia de que aun cuando el escepticismo en términos generales no está difundido en el país, sí un importante número de población declara que la seriedad del cambio climático ha sido exagerada, hallando la existencia de escepticismo de impacto. En este sentido, hay que tener en cuenta que la construcción de encuadres dramáticos o apocalípticos del cambio climático posiblemente aporte a construir este tipo de escepticismo, en aquellas personas que creen que el cambio climático es causado por la actividad humana, pero que al minimizar sus impactos, estarían levantando barreras hacia la acción (Whitmarsh, 2011).

Finalmente, es posible sostener la consistencia entre los encuadres hallados en los medios analizados, y la información disponible respecto a la opinión pública, lo cual en cierta forma confirma el peso que tienen los primeros en la construcción de realidad de sus audiencias.

\section{Mitigación}

En este acápite se presentan los resultados del tema mitigación, para lo cual se la ha definido como: "una intervención humana para reducir las fuentes o mejorar la sumideros de gases de efecto invernadero" (Qin, 2013:1458). Desde la perspectiva del Panel Intergubernamental para el Cambio Climático, al ser éste causado por la acción humana, fundamentalmente por la quema de combustibles fósiles que liberan gases de efecto invernadero (GEI) como el CO2, es posible realizar distintas actividades de mitigación que contribuyan a disminuir la cantidad de dichos gases en la atmósfera.

Este tema a su vez, ha sido subdividido en cuatro encuadres: (i) "reducción de intensidad de emisiones", (ii) "reducción absoluta de emisiones", (iii) "metas de carbono neutralidad" y (iv) "otras acciones de mitigación", tomando como referencia las distinciones realizadas por Fransen y Hatch (2011).

De los cuatro encuadres analizados, tres de ellos presentan noticias en tres de los medios digitales revisados que contienen noticias de Cambio Climático 
Tabla 8: Reportes Balanceados

\begin{tabular}{|ll|l|}
\hline Actores & Ejemplos \\
\hline Centro de Estudios & "En los hielos también puede encontrarse respuesta a una de las preguntas cruciales y que ronda \\
Cientificos de & $\begin{array}{l}\text { Valdivia } \\
\text { (CECs) (N=1) }\end{array}$ & $\begin{array}{l}\text { siempre en los debates respecto del calentamiento global: ¿es el ser humano el responsable?" } \\
\text { (LT130202) } \\
\text { "En sus expediciones, el CECs ha detectado, a través del análisis del monóxido de carbono atrapado } \\
\text { en el hielo, que las concentraciones hoy exceden la variación natural que viene presentándose } \\
\text { durante las últimas decenas de miles de años. En otras palabras, el fenómeno que vemos hoy no } \\
\text { seria de origen natural". (LT130202) }\end{array}$ \\
\hline
\end{tabular}

Fuente: Elaboración propia

en Chile ${ }^{12}$, siendo los medios con mayor número de noticias La Tercera y El Mercurio (ambos con 9), seguido más atrás por La Nación, con 2 noticias.

\section{Reducción de Intensidad de Emisiones}

En este encuadre la mitigación se define como medidas y acciones orientadas a la reducción en la intensidad de emisiones de GEI.

En la muestra analizada, 10 noticias se orientan a este encuadre, siendo sus actores: políticos nacionales, políticos internacionales, empresarios y científicos (Tabla 9).

Entre los temas que destacan está la mención en dos oportunidades del proyecto gubernamental MAPS Chile ${ }^{13}$, que con dos años como plazo (20122013) desarrolló escenarios referenciales de mitigación, analizando distintas opciones para el país.

También es relevante la presencia de autoridades políticas europeas, tanto del gobierno de Inglaterra como el de Suiza, apoyando iniciativas nacionales (Medida Nacionalmente Apropiada de Emisiones, NAMA) y locales (emisiones de carbono en Isla de Juan Fernández) de mitigación de GEI.

El actor que posee el mayor número de apariciones dentro de la narrativa reducción de intensidad de emisiones es la ministra de medioambiente, María Ignacia Benítez, con 5 noticias.

\section{Metas de Carbono Neutralidad}

En este encuadre la mitigación se orienta a la neutralidad de carbono, es decir, a compensar las emisiones de $\mathrm{CO} 2$ con su equivalente en capacidad

\footnotetext{
${ }^{12}$ El Mercurio, La Nación y La Tercera presentan noticias de Cambio Climático en Chile, lo cual no sucede en El Mostrador, medio que utiliza agencias internacionales para publicar acerca del tema.

${ }^{13}$ Mitigation Actions Plans and Scenarios, es una iniciativa basada en un proyecto desarrollado en Sudáfrica entre 2005 y 2008. Actualmente se desarrollan proyectos MAPS en Brasil, Chile, Colombia y Perú.
}

de absorción, por ejemplo, a través de la reforestación ${ }^{14}$. Los bonos de carbono son instrumentos transables en el mercado que permiten conectar la oferta (capacidad de captura de CO2) con la demanda (empresas que desean neutralizar su huella de carbono).

En la muestra estudiada existen cinco noticias orientadas por este encuadre, siendo sus actores empresarios y políticos (nacionales e internacionales). El medio más relevante en este encuadre es El Mercurio, seguido por La Tercera, mientras La Nación no lo presenta (Tabla 10).

Dos empresas apuntan a neutralizar sus emisiones de carbono en forma parcial (demandantes), mientras la tercera apunta a la venta de bonos de carbono para compensar/neutralizar las emisiones de otras empresas (oferente). En política destaca la adopción de una Medida Nacionalmente Apropiada de Mitigación (NAMA) para el Sector Forestal, en convenio con Suiza.

\section{Otras Medidas de Mitigación}

Este encuadre presenta acciones de mitigación distintas a la reducción total o parcial de emisiones de GEI y a la carbono neutralidad. Los actores visibilizados son políticos, científicos y empresarios (Tabla 11), destacando la aparición del ex presidente Sebastián Piñera presentando la Segunda Comunicación Nacional ante la Convención Marco de Naciones Unidas para el Cambio Climático, que contiene dos inventarios de emisiones de GEI actualizados al 2006.

Encontramos 12 noticias en este encuadre. Las medidas de mitigación alternativas que aparecen

\footnotetext{
${ }^{14}$ Costa Rica mediante reforestación ha alcanzado un $81 \%$ de neutralidad de carbono (C-Neutral), siendo el país líder en esta estrategia, que espera convertirlo al 2021 en la primera economía carbono neutral del planeta, con una huella de carbono igual a cero. [en línea] http://www.costaricaon.com/noticias/portada/24608costa-rica-alcanza-cumplimiento-del-81-en-la-metade-c-neutralidad-anuncia-ministro-de-ambiente.html [Consulta: 18/08/14].
} 
Tabla 9: Reducción de intensidad de emisiones

\begin{tabular}{|l|l|}
\hline Actores & Ejemplos \\
\hline $\begin{array}{l}\text { Políticos } \\
\text { Nacionales } \\
(\mathrm{N}=11)\end{array}$ & $\begin{array}{l}\text { "Chile se ha comprometido voluntariamente con acciones nacionales de mitigación con el objeto de limitar } \\
\text { el crecimiento de nuestras emisiones en un 20\% al 2020" (Ministra de Medioambiente, EM131022). }\end{array}$ \\
\hline $\begin{array}{l}\text { Políticos } \\
\text { Internacionales } \\
(\mathrm{N}=3)\end{array}$ & $\begin{array}{l}\text { "( }(. .) \text { el gobierno británico se ha comprometido con el crecimiento y las bajas emisiones de carbono en la } \\
\text { región. Chile es un socio clave para el Reino Unido" (Ministro para Latinoamérica, EM130125.2). }\end{array}$ \\
\hline $\begin{array}{l}\text { Empresarios } \\
(\mathrm{N}=2)\end{array}$ & $\begin{array}{l}\text { "El Centro de Líderes Empresariales para el cambio climático realizó el primer llamado a las empresas a ser } \\
\text { parte de un nuevo modelo económico: bajas emisiones de carbono y producción más competitiva" (Corporate } \\
\text { Leaders Group, LAN111114). }\end{array}$ \\
\hline $\begin{array}{l}\text { Científicos } \\
(\mathrm{N}=2)\end{array}$ & "Deben tomarse medidas para reducir las emisiones de CO2 y así evitar alcanzar puntos críticos en donde no \\
haya marcha atrás" (Julián Ramírez Villegas, Leeds University, LT130504).
\end{tabular}

Fuente: Elaboración propia

Tabla 10: Metas de carbono neutralidad

\begin{tabular}{|l|l|}
\hline Actores & Ejemplos \\
\hline $\begin{array}{l}\text { Empresa 1 Land Rover } \\
\text { (Chile) (N=1) }\end{array}$ & $\begin{array}{l}\text { "Todos los autos emiten dióxido de carbono, pero como Land Rover estamos compensando todas las } \\
\text { emisiones durante su primer año de uso. Es decir, durante sus primeros 20 mil kilómetros, tienen sus } \\
\text { emisiones compensadas" (EM120401). }\end{array}$ \\
\hline $\begin{array}{l}\text { Empresa 2: Lan Airlines } \\
\text { (Sudamérica)(N=1) }\end{array}$ & $\begin{array}{l}\text { "AN definió para el año 2020 la completa medición, verificación y neutralización de su huella de } \\
\text { carbono terrestre en todos los países donde opera en Sudamérica" (EM130129). }\end{array}$ \\
\hline $\begin{array}{l}\text { Empresa 3: E-CL } \\
\text { (Chile) (N=1) }\end{array}$ & $\begin{array}{l}\text { "La generadora eléctrica chilena E-CL (...) presentó ante el Ministerio de Medio Ambiente de Chile su } \\
\text { proyecto parque é́lico Calama, con el objetivo de obtener la validación nacional para tramitar su } \\
\text { participación en el mercado intemacional de bonos de carbono" (EM120920). }\end{array}$ \\
\hline $\begin{array}{l}\text { Política: Lanzamiento } \\
\text { Medida NAMA para el } \\
\begin{array}{l}\text { Sector Forestal (Chile- } \\
\text { Suiza) (N=4) }\end{array}\end{array}$ & $\begin{array}{l}\text { "La NAMA Forestal, presentada por Chile, (...) se hace operativa mediante la denominada Plataforma } \\
\text { de Generación y Comercio de Bonos de Carbono del Sector Forestal de Chile (PBCCh), iniciativa } \\
\text { desarrollada por el Ministerio de Agricultura (...)" (EM130402). }\end{array}$ \\
\hline
\end{tabular}

Fuente: Elaboración propia

son las siguientes: (i) mejoramiento de tenencia y técnicas de manejo forestal para optimizar la captura de carbono, (ii) desarrollo de eficiencia energética e incentivos, (iii) desarrollo tecnológico menos intensivo en GEI, (iv) educación cívica, (v) oportunidades para aliviar la pobreza vía aumento de la competitividad, (vi) etiquetado de productos para entregar mayor información de huella de carbono a los consumidores.

Emergen tres noticias acerca del proyecto MAPS (Mitigation Action Plans and Scenarios), y dos respecto del Centro de Ciencia del Clima y la Resiliencia (CR2).

\section{Discusión}

Siendo Chile un país sudamericano en vías de desarrollo, con un ingreso medio y miembro OCDE, se encuentra en un interregno: no es un país rico y desarrollado, ni tampoco uno en situación de pobreza, lo que complejiza el proceso de decisión en la disyuntiva mitigación/adaptación. En general, se aconseja que los países desarrollados inviertan principalmente en mitigación, y los países en desarrollo en adaptación, básicamente por el uso intensivo que hacen los primeros de combustibles fósiles, y porque los segundos deben invertir menos para acortar brechas con los países desarrollados y entregar así mejores condiciones de vida a sus habitantes, en lo que Giddens (2010) ha denominado "imperativo de desarrollo". En esta dinámica, los países en desarrollo realizan una adaptación reactiva, dado que no disponen de recursos propios para hacer frente a los impactos proyectados, y la cooperación internacional y la transferencia tecnológica juegan un rol fundamental para apoyar el paso hacia una adaptación planificada.

Para ser efectiva, la mitigación debe ser realizada a escala global, y la adaptación a escala local y regional. La mitigación posee una métrica establecida, en cambio conocer los beneficios de la adaptación depende de contextos sociales, económicos y políticos. Los beneficios de la mitigación serán evidenciados en muchas décadas más, por la larga residencia de los GEI en la atmósfera, mientras los de la adaptación son efectivos en el presente, al reducir la vulnerabilidad a la variabilidad climática. A medida que el cambio climático continúe, los beneficios de la adaptación se incrementarán en el tiempo (IPCC, 2013). La pregunta que captura el problema apunta a: “¿Cuáles combinaciones de reducción de emisiones y adaptación pueden reducir mejor los impactos del cambio climático?" (IPCC, 2007:23).

El Panel Intergubernamental para el Cambio 
Tabla 11: Otras acciones de mitigación

\begin{tabular}{|l|l|}
\hline Actores & Ejemplos \\
\hline $\begin{array}{l}\text { Políticos } \\
(\mathrm{N}=9)\end{array}$ & $\begin{array}{l}\text { "(..) nuestro país cuando realiza su balance, se da cuenta que el principal emisor, es sin duda, el sector de la } \\
\text { energía y es ahí donde tenemos que poner una importancia y una prioridad fundamental y el principal captador es } \\
\text { el sector forestal" (Presidente Piñera, EM110830). }\end{array}$ \\
\hline $\begin{array}{l}\text { Científicos } \\
(\mathrm{N}=2)\end{array}$ & $\begin{array}{l}\text { "El estudio entrega, dice, un indicador que pone énfasis en la necesidad de acelerar las medidas de mitigación } \\
\text { respecto de biodiversidad y la vida en las ciudades" (Laura Gallardo - CR2, LT131010). }\end{array}$ \\
\hline $\begin{array}{l}\text { Empresa } \\
(\mathrm{N}=2)\end{array}$ & $\begin{array}{l}\text { (..) el rol del Estos temas; la eliminación de bonento de politicas medioambientales; la imitación de los mercados internacionales } \\
\text { de un desarrollo tecnológico que sea menos intensivo con las emisiones de GEI; y finalmente, el destarrollo de } \\
\text { acciones que busquen educar a la población cívica sobre la importancia del cambio climático" (Corporate Leaders } \\
\text { Group, LAN111114). }\end{array}$ \\
\hline
\end{tabular}

Fuente: Elaboración propia

Climático (IPCC, 2007) plantea que existen disyuntivas y sinergias entre ambas medidas. Dado que una tiene consecuencias para la otra, deben ser diseñadas para aprovechar las complementariedades, reduciendo sus interferencias negativas. Ayers y Huq (2008), a raíz de un estudio de caso en Bangladesh, señalan que más allá de alinear los incentivos, se debe ayudar a conseguir respaldo a la adaptación entre los defensores de la agenda "fuerte" de mitigación, que han sido cautelosos con la adaptación en el pasado.

Somorin et al. (2012), en su análisis de discurso a las políticas de respuesta al cambio climático en el sector forestal del Congo, hallaron tres discursos: políticas sólo de mitigación; políticas separadas de adaptación y mitigación; y políticas integradas de adaptación y mitigación. En este último discurso los encuadres encontrados apuntan a que: (i) existen ventanas de oportunidad para las sinergias; (ii) es posible diseñar una medida para integrar a la otra; (iii) aparentemente poseen marcos institucionales y jurídicos similares para su diseño e implementación; y (iv) el hecho que comparten una política de resultados para la reducción de la pobreza, la conservación de la biodiversidad y el desarrollo. Es relevante destacar que las coaliciones en competencia tras los tres discursos señalados subrayan sus posiciones e intereses con elementos financieros, poder y control, conocimiento, influencia y justicia.

La prensa digital revisada expone la mitigación y la adaptación como medidas complementarias ("medidas de mitigación y adaptación"), sin ahondar en los beneficios y costos de la aplicación de una u otra acción. Que no se definan en forma clara ambos términos puede estar asociado al hecho de que, en general, pocas noticias de ciencia incluyen información acerca del proceso científico (Alley (2012)). Es importante notar que la estructura del formato "noticia" no alcanza en general más allá de las 500 palabras en promedio, por lo cual existe una dificultad para comunicar los contextos de sentido de los eventos presentados, lo cual juega en contra de temáticas complejas. A esto hay que añadir el bajo nivel de comprensión lectora de los adultos chilenos ${ }^{15}$, el muy bajo nivel de escolaridad, y el bajo consumo de literatura en general, situación que Sterman (2011) también destaca para el caso del público estadounidense, existiendo una enorme brecha entre el entendimiento de las personas de las ciencias básicas, y los Summary for Policy Makers, documentos que tienen como intención ser puestos a disposición de los tomadores de decisión y otros actores no científicos, pero que requieren al menos 17 años de estudio para ser comprendidos.

Adicionalmente, los actores visibilizados en la muestra que tienden en las noticias presentadas a constituirse como fuentes primarias de la misma, son fundamentalmente políticos $(n=23)$ representando un $67,6 \%$; más atrás siguen los empresarios $(n=7)$ con un 20,5\%, y finalmente los científicos $(n=4)$ con sólo un 11,8\%. No aparecen actores ciudadanos en estas narrativas. Estas magras cifras de científicos reportando el cambio climático son consistentes con lo que sucede en Estados Unidos. De esta forma, es la política quien define y encuadra el problema y sus soluciones (adaptación y mitigación), construyen casi en solitario la discusión que finaliza en la decisión.

Las señales políticas en las noticias acerca del cambio climático "activan creencias ideológicas y hace de esas creencias predictores de preocupación mayor" que los proyectados por las elites científicas, ya sea existiendo o no un consenso (Alley (2012):178). Esto es relevante, ya que en la muestra estudiada la gran mayoría de los actores políticos presentados son del gobierno o bien partidarios del gobierno de Sebastián Piñera. El riesgo que se presenta es que los actores visibilizados, al poseer una tendencia política homogénea (derecha), teñirían ideológicamente la recepción del público. Conver-

\footnotetext{
${ }^{15}$ El Centro de Microdatos de la Universidad de Chile señala que en 2013 el analfabetismo funcional ?no entender textos- alcanza al $44 \%$ de la población adulta del país, cifras idénticas a las medidas en 1998. [en línea] http://www.lasegunda.com/Noticias/Economia/2013/09/876773/competencias basicas-de-los-chilenos-se-mantienen-estancadas-en-elmenor-nivel-de-ultimos-15-anos [Consulta: 09/07/14]
} 
tir el cambio climático en capital político dificulta el trabajo a largo plazo, dividiendo a la opinión pública en un clivaje ideológico-político (Giddens, 2010).

El proceso de "definición del problema" construye la significancia social de la cuestión tratada, su sentido, las implicancias y la urgencia (Rochefort y Cobb, 2001). El hecho de que la definición de un problema complejo sea realizada eminentemente por la política no es un problema en sí, pues si existe un buen entendimiento del proceso científico podrían perfectamente traducir el amplio consenso científico expresado en el informe del IPCC, así como de las acciones requeridas de mitigación y adaptación. Sterman (2011) comprobaron que adultos con entrenamiento sustantivo en ciencia, tecnología, ingeniería y matemáticas (STEM) sufren sesgos sistemáticos en su juicio, decisiones y evaluaciones de las dinámicas del sistema climático, al evaluar su capacidad de entendimiento del proceso de acumulación (stocks y flujo) del CO2 en estudiantes del Masachusetts Institute of Technology (MIT). Esto muestra que personas con entrenamiento científico, que comprenden los principios de acumulación, no son capaces de comprender el ciclo del carbono o el contexto climático (Sterman, 2011). Desde esta perspectiva no es factible asumir que los actores políticos sean capaces de comprender y comunicar un proceso complejo como el cambio climático hacia las audiencias.

En la muestra analizada la mitigación es presentada principalmente a nivel transnacional, como reuniones y conferencias internacionales, (XVII Conferencia de las Partes de la Convención Marco de Naciones Unidas sobre Cambio Climático, COP 17) y a nivel nacional, tanto como una respuesta del gobierno central (desarrollo de modelos de mitigación) como esfuerzos realizados por actores empresariales (Corporate Leaders Group Chile), consistente con lo hallado por Olausson (2009:426) al analizar tres diarios suecos. Las acciones de mitigación son siempre desplegadas en el macro nivel (transnacional, nacional, empresarial), a excepción del Alcalde de Juan Fernández (EM130402) y la empresa Chilexpress (EM130620), no existiendo noticias que conecten la mitigación con acciones individuales, o bien que den voz a organizaciones no gubernamentales asociadas al tema.

Ockwell et al. (2009) afirman que la comunicación juega un rol fundamental con respecto al compromiso de con estilos de vida bajos en carbono. Señalan que la comunicación tiene dos roles: primero, facilitar la aceptación de regulaciones por parte del público (top-down approach); y segundo, estimular la acción de base mediante un compromiso afectivo y racional con el cambio climático (bottom-up approach). Señalan que sólo la combinación de aproximaciones (top-down/bottom-up) permitiría aumentar los niveles de involucramiento de las personas en el cambio climático, aportando a lidiar con las barreras percibidas a nivel estructural-social y a nivel subjetivo-individual

\section{Adaptación al Cambio Climático}

En este acápite se presentan los resultados del nodo "adaptación al cambio climático", la cual se define como los: "ajustes en sistemas humanos o naturales como respuesta a estímulos climáticos proyectados o reales, o sus efectos, que pueden moderar el daño o aprovechar sus aspectos beneficiosos" (IPCC, 2007:869).

Este nodo a su vez ha sido subdividido en cuatro encuadres: (i) "planificación", (ii) "vulnerabilidad", (iii) "riesgo económico" y (iv) "medidas existentes", tomando como referencia los encuadres hallados por Juhola et al. (2011) en su análisis a documentos de política pública en distintos países europeos.

En la mitad de las noticias analizadas $(29 / 58)^{16}$ se aprecia información referente a la adaptación al cambio climático, en forma implícita o explícita. De los cuatro encuadres analizados, tres de ellos presentan noticias en tres de los medios digitales revisados que contienen noticias de cambio climático en Chile ${ }^{17}$, y sólo en el caso del encuadre "vulnerabilidad" no encontramos referencias de El Mercurio, aun cuando es el medio de la muestra con el mayor número de noticias.

\section{Planificación}

En este encuadre la adaptación al cambio climático se define como integrando procesos de planificación en búsqueda de soluciones a los impactos del cambio climático (Juhola et al., 2011).

Como una forma de organizar la gran cantidad de noticias bajo el encuadre de planificación, se propone un análisis de la emergencia de narrativas en tres niveles distintos, de acuerdo a su grado de concreción en las políticas del país: (i) desde una simple declaración de interés, (ii) como investigación pa-

\footnotetext{
${ }^{16}$ Este número (29 noticias) no considera el fenómeno de yuxtaposición, por el cual una noticia en particular puede contener referencias a distintas narrativas. Al considerar la yuxtaposición dada entre las noticias del nodo "Adaptación", este número sube (58), lo cual se aprecia en el desglose por narrativa analizada (subnodo).

${ }^{17}$ El Mercurio, La Nación y La Tercera presentan noticias de Cambio Climático en Chile, lo cual no sucede en El Mostrador, medio que utiliza agencias internacionales para publicar acerca del tema.
} 
ra generar información para la toma de decisiones, o en el caso de actores políticos y científicos como reuniones internacionales de discusión y coordinación, o bien la creación de comisiones políticas para su discusión, hasta la (iii) elaboración de planes y políticas de adaptación de los sistemas humanos o naturales (Tabla 12).

En el primer caso se trata de una declaración de intenciones, un potencial futuro acerca de lo que vamos o deberíamos hacer para desarrollar capacidades adaptativas. Es un discurso abierto e impreciso, que no posee límites temporales para su concreción en un plan, programa o política.

En el caso de la investigación científica, se menciona la existencia equipos científicos que están en proceso de construcción de información para implementar medidas de adaptación en el país, es decir, buscando informar y legitimar el proceso de toma de decisiones de la autoridad.

Por otra parte, hemos ubicado en un segundo nivel distintas reuniones nacionales e internacionales en que participan actores del país (políticos, científicos) con el fin de intercambiar experiencias y coordinar acciones de adaptación con otros países o bloques, orientados al desarrollo de propuestas de adaptación al cambio climático. También en este segundo nivel es posible ubicar la creación de comisiones políticas para la discusión de medidas de adaptación, ya que al igual que la investigación científica y los encuentros, son instancias de análisis de múltiples opciones de adaptación.

En tercer lugar, se presentan planes y políticas existentes, aun no implementados por el ejecutivo, que definen qué debe hacerse para generar mecanismos de adaptación al cambio climático en Chile.

En la Tabla 18 también apreciamos que los actores $^{18}$ más visibilizados en el discurso de los medios analizados son: políticos (10), científicos (7) y empresarios (2). No aparecen discursos que provengan de la sociedad civil, ONG"s u otros grupos de presión dentro de esta narrativa. Los personajes cuyo discurso emerge en más ocasiones en este encuadre son los políticos: María Ignacia Benítez (Ministra del Medio Ambiente, 2 referencias), Juan Antonio Coloma (Senador UDI, 2 referencias), y Luis Mayol (Ministro de Agricultura, 2 referencias).

\footnotetext{
${ }^{18}$ Los actores contabilizados aquí corresponden a los que expresan un punto de vista: los que "dicen", sea en forma explícita o bien parafraseada en la noticia, y no aquellos que son sólo mencionados en ésta, o son colectivos, como las organizaciones científicas.
}

\section{Vulnerabilidad}

En este encuadre la adaptación es definida como respuesta a la vulnerabilidad percibida a los impactos del cambio climático (Juhola et al., 2011).

La vulnerabilidad aparece en gran medida como escenarios proyectados de impactos negativos provocados por el cambio climático, tanto sociales como para la naturaleza. En dicha dirección predomina el diagnóstico (12 noticias) por sobre las soluciones de adaptación ( 7 noticias), siendo la sequía el peligro con mayor número de menciones (Tabla 13).

Otro elemento surgido del análisis es la mención a la relevancia de educar a la población para hacer frente a los diversos riesgos mencionados (4 noticias).

En términos generales, la vulnerabilidad apunta a riesgos específicos: el sistema hídrico (5 noticias), la energía (2 noticias), la vitivinicultura (2 noticias), entre otros, y en sólo una ocasión se usa el término para dar cuenta de "poblaciones". En este encuadre los actores más mencionados son los científicos (8 noticias), luego los políticos (5), la sociedad civil (2) y la empresa (1). La Tercera destaca por ser el medio digital que entrega más tribuna a los equipos científicos con 6 noticias, seguido más atrás por La Nación (2). Finalmente, es importante señalar que el diario digital emol.com no presenta este encuadre en ninguna noticia.

\section{Riesgo Económico}

En este encuadre, la adaptación es definida como costos y riesgos económicos presentes y futuros (Juhola et al., 2011). Los riesgos con mayor mención están asociados a: la agricultura, empleo y energía (Tabla 14). No sólo emergen riesgos y costos, sino también oportunidades de negocios. La narrativa de riesgo económico aparece en voz de: políticos (9 noticias), científicos (4 noticias), y empresarios (3 noticias).

\section{Medidas Existentes}

En este encuadre la adaptación es definida en términos de medidas existentes, y contrariamente a la planificación, se ocupa del cambio climático actual, no del proyectado (Juhola et al., 2011). Dado el bajo número de casos que ingresan en la categoría (7 noticias), esta narrativa no presenta tendencias relevantes para destacar, no obstante el tema que posee más menciones es la agricultura, especialmente en lo referido al subtema del manejo hídrico del 
Tabla 12: Planificación

\begin{tabular}{|l|l|}
\hline Tipo de Medidas & Ejemplos \\
\hline $\begin{array}{l}\text { Declaración de } \\
\text { Intención } \\
(\mathrm{N}=1)\end{array}$ & $\begin{array}{l}\text { "En concreto, la carta de intenciones que han suscrito permitirá hacer oficial y estrechar la cooperación entre } \\
\text { la CE y la Oficina Nacional de Emergencias (ONEMI), con vistas a reducir los riesgos ante posibles desastres } \\
\text { y mejorar la adaptación a los efectos del cambio climático, tanto a nivel bilateral como regional" (LAN111125). }\end{array}$ \\
\hline $\begin{array}{l}\text { Investigación } \\
\text { Científica } \\
(\mathrm{N}=5)\end{array}$ & $\begin{array}{l}\text { "En el Ministerio del Medio Ambiente dicen que este estudio busca precisamente contar con información } \\
\text { cientifica que permita adoptar politicas públicas que ayuden a contrarrestar estos fenómenos en el largo plazo: } \\
\text { embalses, obras hidráulicas, sistemas de regulación hidrológica y mejoramiento de la red de canales de riego } \\
\text { son algunas de las opciones a las que se puede acceder" (LT130622). }\end{array}$ \\
\hline $\begin{array}{l}\text { Reuniones } \\
(\mathrm{N}=4)\end{array}$ & $\begin{array}{l}\text { "La reunión tiene como objetivo establecer un diálogo entre negociadores jefes latinoamericanos de aquí al } \\
\text { 2015, lo que permitirá identificar convergencias que puedan fortalecer el proceso de mitigación y adaptación a }\end{array}$ \\
\hline $\begin{array}{l}\text { Comisiones } \\
\text { Politicas } \\
(\mathrm{N}=1)\end{array}$ & $\begin{array}{l}\text { "Con el fin de ser un área de trabajo del Consejo Regional Metropolitano en donde sus integrantes sean un } \\
\text { aporte desde el punto de vista de incorporar los elementos de adaptación, a los efectos del cambio climático en } \\
\text { todos los proyectos de inversión de la Región Metropolitana, es que sea crea esta subcomisión" (LT111212). }\end{array}$ \\
\hline $\begin{array}{l}\text { Planes y Políticas } \\
(\mathrm{N}=6)\end{array}$ & "El grupo desarrolló también un "Plan de Adaptación" de 14 medidas que buscarán reducir el impacto de la \\
situación climática en la capital" (EM130124).
\end{tabular}

Fuente: Elaboración propia

Tabla 13: Vulnerabilidad

\begin{tabular}{|l|l|}
\hline Actores & Ejemplos \\
\hline $\begin{array}{l}\text { Sistema Hidrico } \\
(\mathrm{N}=5)\end{array}$ & "En 2012 enfrentamos un tercer año consecutivo de sequí, hemos tenido que declarar 108 comunas en situación \\
& un programa de bombardeo y siembra de nubes en cuatro regiones del país, dijo Mayol" (LAN130115). \\
\hline $\begin{array}{l}\text { Educación } \\
(\mathrm{N}=4)\end{array}$ & "Lo más importante? Educar a la población y a las autoridades "en téminos de conocer este tipo de impactos \\
\hline
\end{tabular}

Fuente: Elaboración propia

país (Tabla 15).

Los actores visibilizados en este encuadre son: políticos (5), científicos (2), sociedad civil (2) y empresariales (1).

\section{Discusión}

Sebastián Vicuña (2012) del Centro de Cambio Global UC, señala que es posible ver la adaptación como una reducción contextual (actual) o como resultado (futuro) de la vulnerabilidad. En esta disyuntiva, los países ricos deberían preocuparse más de resolver la vulnerabilidad futura, y los pobres encargarse más de la actual, situación que para los países de ingreso medio como Chile se torna más compleja, ya que deberían ocuparse de ambas vulnerabilidades, para lo cual debiesen buscar su confluencia. Chile comenzó su camino a la adaptación poniendo un fuerte énfasis en el desarrollo de conocimiento para lidiar con la vulnerabilidad presente, pero en la actualidad estaría girando hacia la resolución de los problemas de vulnerabilidad actual.

Los cuatro encuadres analizados bajo el nodo "adaptación al cambio climático" poseen distinto peso en la muestra estudiada, y remiten a diversas fases del proceso de encuadre, que en forma dinámica, va transformando los temas ambientales en objetos políticos (Juhola et al., 2011). Este proceso o ciclo político de encuadre dinámico comienza con la emergencia de temas ambientales, que van siendo evaluados, y pueden posteriormente ser canonizados como encuadres líderes, para finalmente ser normalizados al formar parte de prácticas y rutinas institucionales (Miller, 2000).

Bassett y Fogelman (2013) hacen notar el extraordinario y creciente nivel de atención que posee el concepto de adaptación en la literatura de cambio climático, luego de un abandono de más de treinta años, fuertemente criticado por sus deficiencias teóricas. Al revisar la conceptualización actual, muestran que hay continuidad con el debate 1970-1980s, más que la aparición de nuevas aproximaciones. De esta forma presentan un análisis de contenido que muestra el predominio (70\%) de enfoque de "adaptación de ajuste", por sobre el de "adaptación transformativa" (3\%). En el caso de las noticias analizadas, también se observa esta dominancia, en que se consideran los impactos climáticos como principal fuente de vulnerabilidad, dejando un menor espacio de atención a las raíces sociales de la vulnerabilidad ("adaptación transformativa"), de tal forma que el discurso de los medios no expresa la necesidad de generar transformaciones estructurales en la vida social e individual, y más bien expresan el punto de vista de reformas incrementales, las cuales aun cuando puedan conducir en el largo plazo a cambios en la conducta de los individuos, no sabemos si bastarán para evitar la degradación del medioambiente a puntos que permitan la sostenibilidad de las generaciones fu- 
Tabla 14: Riesgo Económico

\begin{tabular}{|l|l|}
\hline Actores & Ejemplos \\
\hline $\begin{array}{l}\text { Agricultura } \\
(\mathrm{N}=7)\end{array}$ & $\begin{array}{l}\text { (Alfredo Sfeir) "Queremos recuperar esta agricultura que está siendo perdida, crear más empleos y más fuentes de } \\
\text { crecimientos, hasta productos sofisticados, complementó" (LAN131003). }\end{array}$ \\
\hline $\begin{array}{l}\text { Empleo } \\
(\mathrm{N}=4)\end{array}$ & $\begin{array}{l}\text { "Y es que para Coloma, "estamos ante un proceso de heladas que no tiene precedentes en la historia agrícola" y } \\
\text { condiciones económicas de un amplio sector de Chile" (EM131012). }\end{array}$ \\
\hline
\end{tabular}

Fuente: Elaboración propia

Tabla 15: Medidas Existentes

\begin{tabular}{|l|l|}
\hline Actores & Ejemplos \\
\hline $\begin{array}{l}\text { Agricultura } \\
(\mathrm{N}=4)\end{array}$ & $\begin{array}{l}\text { Tras la cita, Mayol informó que "el ministerio de Agricultura ha declarado a lo menos 52 zonas de emergencia, } \\
\text { hay otras solicitudes más, pero tenemos que estudiarlas con mucha profundidad para que con los recursos que } \\
\text { existen, que son siempre limitados, podamos preferir a aquellos que están con mayor grado de incertidumbre } \\
\text { y de daño por la sequia" (EM120131). }\end{array}$ \\
\hline $\begin{array}{l}\text { Manejo Hídrico } \\
(\mathrm{N}=3)\end{array}$ & $\begin{array}{l}\text { "Nunca en la historia se había hecho tanto por mejorar la eficiencia hídrica del país. Así, desde 2010 a la fecha } \\
\text { hemos tecnificado } 80 \text { mil hectáreas y revestido más de 770 kilómetros de canales" (LAN130714). }\end{array}$ \\
\hline
\end{tabular}

Fuente: Elaboración propia

turas. Si la adaptación sostenible no lidia con los problemas fundamentales del paradigma dominante del desarrollo no sostenible, no será más que un oxímoron (Brown, 2011).

La adaptación en la muestra analizada emerge principalmente como planificación. En el caso de Inglaterra esta narrativa pone el foco en la integración de las preocupaciones de adaptación en los procesos de planificación, con un énfasis en la revisión de las políticas existentes de planificación (Juhola et al., 2011:452). El caso chileno muestra un menor nivel de maduración en la discusión de planificación. Actualmente se están dando los primeros pasos para generar políticas de adaptación, con énfasis en la producción de información científica, o bien encuentros de discusión nacional e internacional, por sobre la generación de planes y programas, existiendo actualmente un borrador de Plan Nacional de Adaptación al Cambio Climático, del Ministerio del Medio Ambiente (2013). La lógica para avanzar en esta materia ha sido sectorial, comenzando con el "Plan Nacional de Adaptación al Cambio Climático (PANCC 2008-2012)", al que le siguieron planes sectoriales, como el "Plan de Adaptación al Cambio Climático para el sector silvoagropecuario" y el "Plan de Adaptación al Cambio Climático para la biodiversidad" 19 .

En segundo lugar en orden de relevancia surge el encuadre de vulnerabilidad. En el caso de Suecia este encuadre se encuentra conectado a eventos climáticos extremos. La comunidad científica y política fueron reunidas en una Comisión de Cam-

\footnotetext{
${ }^{19} \mathrm{Se}$ encuentran en distintas fases de diseño los planes de adaptación: para el sector pesca y acuicultura, para el sector salud, para la infraestructura, para ciudades, para el sector turismo, para el sector energía, y para los recursos hídricos (MMA, 2014).
}

bio Climático y Vulnerabilidad (2005-2007) con objeto de investigar para "complementar la estrategia política sueca con la adaptación" (Juhola et al., 2011:451). En Chile, en cambio, se observa a la vulnerabilidad como una proyección de impactos futuros, es decir, no se percibe al cambio climático actuando en el presente. Además, no se ahonda en los aspectos sociales e históricos de la vulnerabilidad (Bassett y Fogelman, 2013), pues la forma en cómo concibamos la vulnerabilidad inevitablemente va a influenciar la manera en cómo concibamos la adaptación. Ambos elementos generan grados de disociación en la comprensión de las audiencias respecto a quiénes son las poblaciones más expuestas y vulnerables al cambio climático, y la necesidad de actuar disminuyendo la vulnerabilidad económica y social actual.

En tercer lugar, aparece la narrativa de "riesgo económico". En Inglaterra esta narrativa forma parte de la política ambiental tradicional, especialmente a través de reportes que detallan los costos y beneficios de la adaptación, incluyendo a múltiples actores en vez de considerar el tema como de exclusiva responsabilidad gubernamental. En la muestra analizada para el caso chileno, el riesgo económico también encuentra amplio respaldo en la política (8 actores), y de igual manera es vista no sólo como costos sino también como oportunidades de negocio (7 noticias).

En Chile, a diferencia de lo ocurrido en Inglaterra (Uusi-Rauva y Tienari, 2010), donde el encuadre positivo de oportunidad económica es realizado por The Guardian, diario de centro izquierda liberal, quienes presentan este encuadre son los medios de derecha (emol.com=3; latercera.com=3). En cambio, un medio de centro-derecha como The Daily Telegraph presenta un encuadre negativo, acen- 
tuando la amenaza para la competitividad industrial del sistema de comercio de emisiones (ETS). Esta visión (positiva) de oportunidad económica apunta al encuadre de modernización ecológica, sustentado en las últimas décadas en Inglaterra por el gobierno del New Labour (Uusi-Rauva y Tienari, 2010), que contrasta con la posición emergente en los medios asociados a la centro-izquierda chilena (lanacion.cl=1), que tienden a connotar los efectos negativos, como la pérdida de empleos y de infraestructura.

Carter (2014) destaca una serie de eventos realizados tanto por el tercer sector como por parte importante del sector industrial inglés, así como su difusión por parte de los medios de comunicación llevaron a que el cambio climático y los temas ambientales fuesen posicionados como temas relevantes de la agenda pública como nunca antes durante el período 2006-2010. En este contexto, los partidos políticos ingleses comenzaron a competir por posicionarse favorablemente en el tema, en la discusión de la Climate Change and Energy Policy (CCEP), dado que "fueron conscientes de los datos de las encuestas que mostraban gran saliencia a los temas medioambientales" (Carter, 2014:428).

Esta visión positiva es discutida fuertemente, puesto que reduce y simplifica el concepto de desarrollo, lo cual es central especialmente para los países no desarrollados. Para Cannon y MullerMahn (2010) es fundamental separar el concepto de "desarrollo" del de "crecimiento económico", que han tendido a ser confundidos desde los 80s, y que en la muestra analizada tienden a conjuntarse en la narrativa de "oportunidad económica". Esta narrativa alberga en su interior la idea de que el crecimiento económico y acumulación de riqueza de los grupos más ricos tenderá eventualmente a permear hacia las capas inferiores de la sociedad ('trickledown theory"; "teoría del chorreo"), idea defendida por think tanks de derecha ${ }^{20}$ en Chile, fieles al modelo económico implantado por el gobierno militar durante los $80 \mathrm{~s}$, y que no ha podido ser contestada en forma efectiva por los gobiernos democráticos de las últimas décadas. Esta teoría probablemente ha llegado a sus límites, dejando un balance importante de asimetrías y desigualdad.

El riesgo económico en la muestra estudiada es encuadrado como riesgo y oportunidad para aquellos que han resultado "ganadores" del proceso de

\footnotetext{
${ }^{20}$ Libertad y Desarrollo. Centro de Estudios Públicos. Fundación Jaime Guzmán. El discurso neo liberal afirma que la mejor forma de reducir la pobreza es a través del crecimiento económico. Al respecto, la New Economics Foundation (NEF) plantea que: "El crecimiento económico global es una vía extremadamente ineficiente para alcanzar la reducción de la pobreza y está llegando a ser cada vez menos efectiva" (NEF 2006:3).
}

crecimiento económico del país desde la década del 80, con un muy bajo nivel de menciones hacia los grupos más vulnerables en términos socioeconómicos, que tienden sistemáticamente a ser los más expuestos al cambio climático. Así, el crecimiento económico no es en sí adaptación al cambio climático, y sí lo es un concepto de "desarrollo con sentido", abocado directamente a mejorar la vida de las personas, que no sea un efecto secundario de lo que otros actores (corporaciones o gobiernos) hagan en su búsqueda de ganancia y crecimiento (Cannon y Muller-Mahn, 2010). De esta forma se habla de un "sesgo económico" de los tomadores de decisión, en que los problemas son definidos exclusivamente como un asunto de calcular costos y beneficios (Dewulf 2013).

Las interacciones entre estrategias de adaptación al cambio climático y políticas de desarrollo es un tema de análisis emergente, manifestado en la gran cantidad de publicaciones que desde mediados de los 90 s se abocan a temas como la adaptación, la vulnerabilidad y la resiliencia (Cannon y MullerMahn, 2010). En este interés existirían dos brechas, de acuerdo a la bibliometría realizada por Janssen et al. (2006): tanto por la existencia de un patrón de fragmentación en las relaciones entre vulnerabilidad y resiliencia, y el hecho de que la conceptualización de cambio climático y adaptación ha sido largamente dominada por las ciencias naturales. Ambos déficits reflejan la necesidad de un compromiso más intensivo por parte de las ciencias sociales en el tema. En esta dirección Nisbet et al. (2010) abogan por generar nuevas sinergias para comprometer a la sociedad con el cambio climático, reuniendo las "cuatro culturas" (ciencias ambientales; artes y profesiones creativas; filosofía y religión; ciencias sociales) para acelerar dicho giro societal.

Finalmente, el encuadre "medidas existentes" muestra una tendencia de que en nuestro país las políticas se están orientando hacia la agroindustria.

\section{Resiliencia al cambio climático}

En este acápite se presentan los resultados del tema "resiliencia al cambio climático", para lo cual se ha definido la resiliencia como la: "capacidad de un sistema social o ecológico para absorber una alteración sin perder ni su estructura básica o sus modos de funcionamiento, ni su capacidad de autoorganización, ni su capacidad de adaptación al estrés y al cambio" (Pachauri et al. 2007:87), en que destacan "las dinámicas no lineales, los umbrales, la incertidumbre y la sorpresa" (Folke 2006:253). 


\section{Resultados}

La resiliencia aparece mencionada sólo en tres noticias (3/58), asociada siempre al Centro de Ciencia del Clima y la Resiliencia (CR2), proyecto FONDAP que reúne a la Universidad de Chile, la Universidad Austral y la Universidad de Concepción, financiado por la Comisión Nacional de Ciencia y Tecnología (CONICYT). Los medios que presentan este encuadre son La Tercera y La Nación, siendo sus protagonistas la ciencia y la política (Tabla 16).

\section{Discusión}

La resiliencia en las noticias obtenidas de la muestra emerge nominalmente, asociada siempre al Centro de Ciencia del Clima y la Resiliencia (CR2), por lo que no alcanza a constituirse como un encuadre del cambio climático en nuestro país. Es importante señalar que es también considerada como un encuadre emergente de la adaptación al cambio climático (Cannon et al. 2010; McEvoy et al. 2013).

Aun cuando el concepto no deja de ser controversial y resistido, ha ganado un lugar tanto en el discurso académico como en el político (Aldunce 2013; Aldunce et al. 2014). Las críticas que se le han realizado afirman que al cambiar el énfasis desde la vulnerabilidad hacia la resiliencia (encuadre más positivo), posicionando a los afectados por los desastres no como víctimas necesitadas de ayuda, sino como personas con capacidad para accionar y movilizar recursos. Se trataría de un concepto abstracto y maleable, que da paso a políticas vagas, siendo fácilmente manipulable para conseguir diferentes objetivos, dejando de lado cuestiones importantes como la ausencia de poder y agencia por parte de los afectados (Aldunce 2013).

Cannon y Muller-Mahn (2010) señalan a la resiliencia como un concepto "peligroso", que remueve la connotación relativa al poder que posee el concepto de vulnerabilidad, pudiendo potencialmente hacer lo mismo con el concepto de adaptación. Afirman que trasplantar en forma acrítica un concepto desde los sistemas naturales a los sistemas humanos resulta inadecuado, puesto que éstos últimos incorporan relaciones de poder que no son capturadas por las analogías de "ser auto-regulado" o "racional" (Cannon 2008).

A la luz de las tragedias ocurridas durante el año en curso en Chile ${ }^{21}$, es posible afirmar que esta narrativa tenderá a mostrar una mayor presencia en el futuro, puesto que se encuentra ligada a la ges-

\footnotetext{
${ }^{21}$ Terremoto en las regiones nortinas de Arica y Parinacota y Tarapacá (1 de abril, 2014); "Incendio perfecto" en la ciudad de Valparaíso (12 de abril, 2014).
}

tión de riesgo de desastres (DRM, disaster risk management). En el caso de Australia, los tomadores de decisión relacionados con la gestión de desastres están utilizando el concepto intensivamente en documentos a nivel local, nacional e internacional (Aldunce 2013).

Elementos clave en la relación resiliencia-DRM son la incertidumbre y la participación de todos los involucrados en la búsqueda de soluciones. Siendo la diversidad, redundancia e interdependencia factores centrales para construir resiliencia frente a desastres, es una estrategia que apunta a considerar la incertidumbre como oportunidad para explorar públicamente las opciones disponibles, con el objetivo de aprender, adaptarse y mejorar las capacidades de DRM (Aldunce 2013).

Bohensky y Leitch (2013) muestran que el discurso de los medios puede darle soporte a la resiliencia (ideas de espíritu comunitario, de cohesión, entre otras) o bien minarla (ausencia de reflexión crítica respecto a la responsabilidad), en tanto sean capaces de aportar a la generación de aprendizajes para no repetir los errores cometidos y expuestos durante y después del desastre.

\section{Esperar y Observar}

En este acápite se presentan del tema que se ha denominado como "esperar y observar", encuadre que sugiere esperar por más evidencia o información científica antes de tomar acción (Aldunce 2013).

\section{Resultados}

En la muestra analizada encontramos 5 noticias que presentan este encuadre, (3 de El Mercurio, 1 de La Nación, 1 de La Tercera), siendo sus actores políticos. El personaje más destacado en la prensa es María Ignacia Benítez (3 noticias), ex Ministra de Medio Ambiente (Tabla 17).

\section{Discusión}

El cambio climático no sólo contiene gran incertidumbre, sino que plantea ciertamente la emergencia de eventos sorpresivos asociados al crecimiento de la energía en el sistema climático, lo que a su vez conlleva nuevos riesgos en: los tipos de desastre que hacen vulnerable a una región (de no-desastres en el pasado a más eventos catastróficos); cambios en el tipo de peligros (de sequías a inundaciones); o cambio en las intensidades y magnitudes de los peligros ya conocidos (Prabhakar 2009). 
Tabla 16: Resiliencia al Cambio Climático

\begin{tabular}{|l|l|}
\hline Actores & Ejemplos \\
\hline $\begin{array}{l}\text { Política: Comisión Nacional } \\
\text { de Investigación Científica y } \\
\text { Tecnológica (CONICYT) } \\
\text { (N=1) }\end{array}$ & "LA CIENCIA ESTA DE FIESTA: \$24 MIL MILLONES PARA 6 CENTROS DE \\
\hline INVESTGACION (...) Centro de Ciencia del Clima y la Resiliencia" (LAN121022).
\end{tabular}

Fuente: Elaboración propia

Tabla 17: Esperar y Observar

\begin{tabular}{|c|c|c|}
\hline Actores & & Ejemplos \\
\hline \multirow[t]{2}{*}{ Politicos } & \multirow[t]{2}{*}{$(\mathrm{N}=5)$} & $\begin{array}{l}\text { "Queremos tener información documentada para definir nuestro compromiso" (María Ignacia } \\
\text { Benitez) (EM130506). } \\
\text { "El Presidente decidió que se formará una comisión de técnicos para analizar con la mayor cantidad } \\
\text { de información que tengamos la situación actual y la situación que viene debido al cambio climático } \\
\text { y poder trabajar en un programa o plan de largo plazo (...)", señaló Mayol" (EM120131). }\end{array}$ \\
\hline & & $\begin{array}{l}\text { "Todos queremos mucho el medio ambiente, pero detrás hay mucha ingeniería y mucha regulación", } \\
\text { aseguró Benitez, ministra desde } 2010 \text { (...)" (LT130506). }\end{array}$ \\
\hline
\end{tabular}

Fuente: Elaboración propia

Por otra parte, las metodologías de evaluación de riesgo descansan en forma importante en el registro histórico de peligros sufridos por un territorio (Prabhakar 2009). En este escenario, los tomadores de decisión suelen entrar en dos grupos: aquellos que invocando el principio de precaución, dicen que es necesario actuar de inmediato para reducir los impactos del cambio climático, y también los que argumentan que el curso de acción más prudente es esperar para tener mayor conocimiento antes de actuar.

El hecho de que en la muestra analizada los tomadores de decisión aparezcan optando por este último encuadre puede ayudarnos a orientar las posibilidades que tiene la política chilena para actuar frente a escenarios de incertidumbre. Aún más, siendo Estados Unidos el principal modelo político del país (factor externo), es fácil comprender la decisión de esperar y observar.

La dificultad para realizar transformaciones al modelo socioeconómico heredado del gobierno militar de Pinochet (1973-1990), nos muestra también la resistencia al cambio de la clase política chilena (factor interno), en que las innovaciones ocurren no en forma incremental, como resultado de ajustes y aprendizajes iterativos, sino en forma explosiva, usualmente cuando la agenda pública se ha alejado de manera importante del centro político. Ideologizar o politizar un tema tan relevante como el cambio climático es una estrategia que a largo plazo juega en contra de la convergencia política que dará soporte a la acción del Estado. Por este motivo, la tendencia mostrada por las elites políticas no favorece la acción frente a este tema (Giddens 2010).

Según el índice internacional de Hofstede ${ }^{22}$, Chile posee un puntaje de 86 de aversión a la incertidumbre, dentro de un máximo de 100, siendo el más alto en América Latina. En este contexto, los embates de la naturaleza que debe resistir constantemente el país grafican la ausencia de planificación y mirada prospectiva hacia fenómenos con alta probabilidad y certeza de ocurrencia.

Este contexto político, caracterizado por la aversión al riesgo, sumado a la ausencia de planificación estatal, daría cuenta de la dificultad que tienen las elites del país para enfrentar un escenario de cambios constantes y eventos sorpresivos. Existe una distancia entre el discurso y las acciones de las elites chilenas frente al cambio climático (Parker et al. 2013), paso que se dará sólo cuando la información, comunicación y atención de las elites sea direccionada por los siguientes factores: (a) cambios en los marcos regulatorios y las instituciones (especialmente mediante compromisos internacionales),

\footnotetext{
${ }^{22}$ Cultural Tools, Country Comparison. The Hofstede Centre. [en línea] http://geert-hofstede.com/chile.html [Consulta: 01/08/2014]
} 
y (b) con la presión social de una ciudadanía consciente y activa en problemas ambientales (Parker et al. 2013).

Quizá por estos motivos Chile destaca en el mundo como un país capaz de enfrentar desastres y emergencias con gran aplomo y resolución ${ }^{23}$ : al no existir una cultura de planificación, lo que tendríamos es una cultura de improvisación. La inmovilidad de las elites para realizar cambios contrasta así con la capacidad de la ciudadanía para enfrentar los más variados peligros. También es importante señalar que el país probablemente no cuenta con los recursos para desarrollar capacidades de adaptación en su población, altamente segregada y con un alto nivel de desigualdad.

Más allá de estas consideraciones, llama la atención la homogeneidad de los actores visibilizados en la muestra (3 noticias de la ministra de medioambiente), lo cual hace del "esperar y observar" un encuadre posicionado en la agenda pública, que en cierta forma esconde otras sensibilidades, probablemente más próximas al principio de precaución.

\section{Reflexiones}

\section{Cambio climático como "mal públi- co": la toma de decisión}

El cambio climático abrupto es una aproximación científica basada en que los modelos predictivos usados comúnmente proyectan linealmente el proceso de cambio del clima global, aun cuando existe evidencia en los testigos de hielo analizados de la ocurrencia de cambios climáticos abruptos en la tierra, causados por puntos de inflexión (tipping points) en que pequeñas perturbaciones pueden alterar cualitativamente el estado de desarrollo de un sistema. El propósito de mencionar esta línea de investigación es señalar que la incertidumbre juega un papel más crucial hacia el espectro negativo de posibilidades, y que por ello no debe ser excusa para la inacción, en línea con el principio de precaución (Commonwealth Secretariat 2009).

La Estabilidad del Clima Global (ECG) es considerada un "bien público global" ${ }^{24}$, puesto que es un

\footnotetext{
23 "Secretario de Defensa de EE.UU destaca respuesta de Chile ante catástrofes". En la noticia se presenta al país "como un modelo para toda la región" (El Mercurio, 16 de Abril de 2014). [en línea] http://www.emol.com/noticias/nacional/2014/04/16/655706/ de-defensa-de-eeuu-destaca-respuesta-de-chile-antecatastrofes.html [Consulta: 01/08/2014]

${ }^{24}$ En general, los bienes públicos globales están infrafinanciados. Para una crítica al "rol sin mandato" del Banco Mundial respecto del Cambio Climático, ver: Nancy Birdsall
}

bien indivisible, no-rival (la ganancia de un país al contar con un clima estable no previene que otros a su vez puedan disfrutarlo) y no-exclusivo (no existen mecanismos para excluir a un país del beneficio de contar con un clima estable) (ODS 2002). Desde esta perspectiva el cambio climático es un "mal público", que representa una mala provisión (por sobreuso) de ECG, que puede traducirse en pérdidas económicas, de vidas, cambios en la calidad de la vida, así como pérdidas en la biodiversidad. Los tomadores de decisión deben por tanto buscar equilibrios de las políticas hacia una provisión efectiva de ECG que sea lo más compatible posible con los problemas actuales y futuros, evaluando distintos riesgos en contextos de incertidumbre. Dentro de un proceso colectivo, en que la política, la ciencia y el público co-construyen representaciones del medioambiente y sus problemas, y por lo tanto con un rol vital de los medios masivos para su difusión en el espacio público (Boykoff 2009). Para el caso de los congresistas peruanos se afirma que el acceso limitado a información confiable acerca del cambio climático hace que los tomadores de decisión se apoyen en fuentes menos confiables, como los medios tradicionales y la web (Takahashi y Meisner 2013a), como probablemente también es el caso de los chilenos.

Los tomadores de decisión deben tener presentes las potenciales consecuencias catastróficas derivadas de cambios climáticos abruptos, con el objetivo de tomar las medidas adecuadas: en los países desarrollados, mediante acciones de mitigación, y en los en desarrollo, especialmente mediante la adaptación. El desafío es conseguir alinear a los diferentes países en torno a estas acciones, especialmente en lo referido a las acciones de mitigación que los países más contaminantes puedan implementar, como el acuerdo recientemente alcanzado entre China y Estados Unidos, de reducción de contaminantes a partir del 2030 el primero, y de bajar las emisiones entre un $26 \%$ y $28 \%$ el 2025 para el segundo, tomando como referencia el 2005.

\section{Tomadores de decisión: ¿solos en la decisión?}

Los resultados del análisis a los medios digitales de prensa escrita muestran que los actores con mayor presencia en las noticias de cambio climático en Chile son los políticos, especialmente de las agencias gubernamentales, consistente con lo halladeeretafidotson et al. (2012) durante los años 2003, 2005 y 2007. Por otra parte, los actores invisibilizados son los ciudadanos, tanto organizados como individualmente. Esta asimetría ayuda a construir

(2010) 
el cambio climático como un problema concerniente al Estado, lejos de la vida diaria de la gran mayoría de personas comunes, al no reconocerse como parte del problema ni de sus soluciones.

El corpus de noticias analizado muestra, salvo contadas excepciones, a actores políticos de nivel central/nacional, sin dar espacio a los niveles regionales y locales. Sea cual fuere la causa, resulta preocupante, pues dar respuestas al cambio climático, especialmente a eventos sorpresivos y abruptos requiere de lo que se ha denominado "gobernanza policéntrica", pues es la única estructura capaz de reaccionar eficaz y eficientemente a nivel local y territorial (Biggs et al. 2011).

Esta visión "de arriba hacia abajo" se ajusta a la tradición histórico-política del país. Las elites y sus representantes definen los límites y cursos de decisión plausibles, y las mayorías delegan dicha potestad de decisión, generando entre ambos una complicidad tácita asociada a una normalidad. En momentos de crisis, este mecanismo deja de ser legítimo para sectores activos de la ciudadanía, que presionan por participación en la definición de la agenda pública a través de la organización de movimientos sociales. La pérdida de legitimidad de la lógica representacional está ligada al problema del agente-principal, en la medida en que el principal (el electorado, la ciudadanía) delega autoridad a un agente (político) que posee incentivos para desviarse del mandato del principal, actuando en beneficio propio, gracias a la asimetría de información existente entre ambos (el agente siempre posee más información). Los medios analizados en forma sistemática generan distancia de la ciudadanía respecto a su rol como principal, minusvalorando su capacidad de agencia, así como sus deberes y derechos en la creación de valor público mediante el cuidado de un bien público como la Estabilidad Climática Global.

En esta asimetría (supra visibilidad de la política/invisibilidad de la ciudadanía), los discursos no son sólo prácticas de construcción de opinión o de toma de decisión, sino que expresan relaciones sociales, intereses particulares, y el poder (Cannon y Muller-Mahn, 2010: 631): son medios para expandir el control. Esto es relevante pues no se trata de baja visibilidad, sino que la muestra estudiada no presenta a la ciudadanía, marginalización que puede referirnos a estructuras subyacentes de nuestra vida social, caracterizada por el desanclaje (Giddens, 1994) de la política respecto a sus contextos locales de interacción. Así, se estaría generando una percepción distorsionada de la toma de decisión, en que la ciudadanía sólo posee agencia al momento de sufragar, y que en el intervalo entre una elección y la siguiente son los tomadores de decisión los únicos participantes en la definición de los mejores modos y vías de acción.

A diferencia de lo ocurrido en países donde existe un debate importante en la política, expresada incluso como "batallas discursivas" (Backstrand y Lovbrand, 2006), en Chile los medios estudiados visibilizan actores que poseen un importante nivel de consenso, razón por la que no emergen antagonismos o niveles de divergencia relevantes. Cabe mencionar que la opinión pública chilena valora mal a los actores conflictivos, los que no logran las simpatías del votante de la mediana, sector fundamental para ganar el gobierno.

Sin el contrapeso de los discursos, encuadres y narrativas del mundo científico, y en especial de los de la ciudadanía, existe el peligro de que las decisiones adoptadas se alejen metódicamente del "óptimo", lugar virtual que se encontraría en la coincidencia de todos los actores de la sociedad. Este desequilibrio favorecería ciertas medidas en desmedro de otras, evaluando los riesgos con información parcial y/o sesgada, en particular los asociados a comunidades locales y marginales, es decir, las que presentan los mayores niveles de exposición y vulnerabilidad a los impactos negativos del cambio climático.

Dewulf (2013) analizó los encuadres de la adaptación hallando dos posiciones distintas: (i) encuadres tecnocientíficos de la adaptación, que la definen como un "problema técnico domésticado", y (ii) encuadres sociopolíticos de la adaptación, que la definen como "problema de gobernanza maldito" (wicked), donde las incertidumbres, instituciones y equidad necesitan ser tomadas en cuenta. En la muestra analizada se observa el encuadre tecnocientífico, pero los encuadres sociopolíticos están ausentes. Los políticos nacionales se alinean con los científicos en la búsqueda de información, sin dedicar espacio a problemas políticos o de gobernanza.

Los límites de la adaptación dependen en última instancia de los valores de los individuos. Si estos valores no son discutidos, pueden actuar como límites (Adger et al., 2009). Los valores que sustentan las acciones de adaptación son más diversos y contradictorios a medida que avanzamos de una escala pequeña (local) hacia una más grande (nacional), motivo por el que es necesario que los tomadores de decisión expliciten sus valores en relación a sus preferencias respecto al bienestar y aversión al riesgo, situación que se dificulta al no tener una contraparte en el espacio público que pueda exigir la discusión de dichas preferencias.

Dewulf (2013) señala la existencia de dos trampas que deben evitarse al encuadrar la adaptación: i) que los actores involucrados en los procesos de 
adaptación queden atrapados en un encuadre particular sin ser completamente consciente, solo descubriendo tardíamente las limitaciones o consecuencias no deseadas; y ii) que los actores queden atrapados en un combate de encuadres, en donde diferentes actores tratan de que los suyos prevalezcan, produciendo controversias políticas, conflictos intratables, o bien paralizando la toma de decisiones.

En la muestra estudiada se observa que los medios analizados dan cuenta de la primera "trampa", al no incluir a otros actores y encuadres, muy lejos del polo de encuadres controversiales, mostrando una mirada monolítica al problema y sus soluciones.

\section{Personas y comunidades: potencial perdido para la acción climática}

La manera en cómo es representado el cambio climático en los medios resulta fundamental para informar a las personas acerca de cuáles son sus deberes y derechos respecto a una adecuada provisión de Estabilidad Climática Global. Las percepciones, valores y normas pueden facilitar o constreñir la acción, promoviendo o limitando la mitigación y la adaptación, y por el hecho de que estas percepciones, valores y normas son construcciones que a escala societal dependen en gran medida de aquello que es visibilizado e invisibilizado por los medios de comunicación masivos.

Cuando las noticias invisibilizan a las personas y a las comunidades sistemáticamente respecto a su rol frente al cambio climático, lo que en forma latente se está incubando es el desastre. Notamos así que la vulnerabilidad puede ser creada también por condiciones deficientes de circulación del conocimiento. Es por ello que la comunicación de información del cambio climático, así como la construcción de conciencia en relación a sus impactos es parte de las acciones asociadas al desarrollo de capacidad adaptativa (Adger et al., 2009).

Afrontar la mitigación y la adaptación requiere de estrategias que integren formas de interjuego entre políticas de "arriba hacia abajo" y de "abajo hacia arriba" (Ockwell et al., 2009; Cannon y Muller-Mahn, 2010), por lo que apartar a las personas y las comunidades locales de las noticias genera una mala comprensión (adquisición y empleo de conocimiento factual correcto), percepciones erradas (miradas e interpretaciones basadas es creencias y entendimiento) y bajo compromiso (estado de conexión personal que incluye dimensiones cognitivas, afectivas y de comportamiento) de parte del público (J. y C., 2011).
Se plantea esta situación como un potencial perdido para la acción climática, ya que a nivel internacional nuestra población muestra un alto respaldo (75\%) al cambio climático antropogénico, muy por sobre los Estados Unidos (49\%). Este porcentaje es importante, por cuanto la población que declara tener conocimiento del cambio climático es casi la misma (73\%), muy por debajo de lo sucedido en Estados Unidos (97\%). Esto es consistente con lo hallado por Kim y Wolinsky-Nahmias (2014) respecto a que los países no desarrollados entregan más soporte a ciertas políticas climáticas, y que los países más vulnerables a los efectos del cambio climático son aquellos con mayor disposición a pagar, que corresponden nuevamente a los no desarrollados.

\section{Cohesión de las elites}

El estudio de Parker et al. (2013) muestra que las elites chilenas más asociadas al llamado "paradigma social dominante" (DSP, siglas en inglés) son las vinculadas a los mercados globales de alimentos y los exportadores agrícolas. El DSP es un constructo acuñado por Dunlap y Van Liere (1984) que busca capturar los valores y estilos de vida occidentales que han promovido la destrucción del medioambiente en Estados Unidos, que incluye en sus dimensiones: apoyo a un gobierno limitado, economía de libre mercado, creencia en los beneficios del crecimiento económico, apoyo al mantenimiento del statu quo, fe en la ciencia y la tecnología, creencia en la abundancia de los recursos naturales y fe en un futuro de prosperidad. Las elites de la minería, la construcción, el transporte y la energía muestran visiones más polarizadas entre los que apoyan el DSP y aquellos que dan soporte a la necesidad de implementar medidas de adaptación y mitigación al cambio climático.

Takahashi y Meisner (2013) plantean que en Perú el tema no es discutido en términos de amenaza al desarrollo económico del país, y que cuando los temas son percibidos como amenazas al desarrollo económico son rápidamente descartados como "antidesarrollo", situación que sería similar en Chile. En los medios peruanos no emerge el encuadre de oportunidad económica, a diferencia de la muestra analizada, y los actores económicos (negocios/industria) son utilizados en forma muy limitada como fuentes de información.

La elite política de derecha y centro-derecha tiende a localizarse en posiciones más intermedias, pero sin prestar apoyo a paradigmas alternativos. La centro-izquierda en cambio, al igual que los líderes ambientales dan soporte a paradigmas alternativos, también conocido como "polo verde" del espectro 
(Parker et al., 2013). Sus discursos expresan que tomar acciones para limitar el cambio climático responde a factores que van más allá de su responsabilidad, apuntando a: (a) la limitada información provista por las agencias oficiales y los medios, (b) falta de claridad de los científicos, (c) medidas insuficientes a nivel institucional, (d) causas y condiciones estructurales e institucionales, y (e) responsabilidad del Estado y fallas regulatorias (no fallas de los negocios) (Parker et al., 2013).

Vemos así que nuestras elites políticas y económicas no se sienten responsables en la acción climática, responsabilizando a los medios de comunicación por la calidad de la información provista: se encuentran esperando y observando, por ello los autores señalan que mientras la comunidad internacional (top-down) y la presión social (bottom-up) no actúen, no podemos esperar a que tomen las medidas y realicen los cambios necesarios para frenar el cambio climático.

\section{Emergencia de movimientos socioam- bientales: ¿cambiarán la agenda públi- ca?}

Al observar las noticias en la muestra estudiada, da la impresión que nuestro país es un "alumno aventajado" a nivel internacional en lo concerniente a las acciones y compromisos adoptados para la mitigación y adaptación al cambio climático, avanzando de acuerdo a una agenda de punta, participando activamente en foros y encuentros multilaterales.

Por otra parte, en el ranking de calidad ambiental OCDE aparece en el antepenúltimo puesto, bajo Rusia, México y Grecia. Además, dentro del Índice de Mejor Vida (OCDE) compuesto por 11 dimensiones del país, "medioambiente" es la penúltima $(3.3 / 10)$, solo mejor que "ingreso" (1.1/10). Este puntaje responde a la matriz extractiva de la minería, intensiva en el consumo de agua y electricidad en el norte árido, y al uso de leña para calentar los hogares sureños, así como a las condiciones de ventilación de nuestra capital.

Esta brecha entre las noticias analizadas y la percepción que tienen las personas de la calidad del medioambiente, expresan, por una parte, la desconexión existente entre las elites y la vida cotidiana de las mayorías. Por otra parte, que los medios de prensa buscan "inculcar y defender el orden del día económico, social y político de los grupos privilegiados que dominan el Estado y la sociedad del país" (Chomsky y Herman, 2009).

De esta forma, desde los medios de comunicación se está construyendo un imaginario del medioam- biente que es radicalmente distinto al que experimentan grandes cantidades de población urbana y rural de nuestro país.

En otro orden, se aprecia que los actores políticos fundamentan su inmovilidad haciendo uso del encuadre "observar y esperar", alegando que la incertidumbre requiere ser despejada con estudios más profundos, en curso o futuros.

Al respecto Adger et al. (2009) apuntan a que la sociedad puede adaptarse aun con incertidumbre, señalando que la ausencia de conocimiento exacto del clima futuro ha sido falsamente construida como un límite absoluto para la adaptación. Afirman que existe mucha evidencia de que el clima es solo uno de muchos procesos inciertos que influencian a la sociedad y sus actividades, proponiendo la "toma de decisiones robusta" como un enfoque pertinente para identificar y evaluar estrategias robustas al analizar sistemáticamente el comportamiento de las estrategias de adaptación entre un amplio rango de futuros posibles. Así, la espera de las elites políticas no tiene asidero, tanto por las acciones que respaldan en otros ámbitos que también poseen incertidumbre, como por la existencia de estrategias de toma de decisión robusta.

En todas las situaciones antes señaladas se aprecia la convergencia de los encuadres presentados en los medios analizados (especialmente en los políti$\cos$ y empresariales), que van a generar una sensación de calma y cohesión, alejada del conflicto, sensación que no se corresponde con una serie de acciones locales y ciudadanas que presentan resistencia a cómo se han llevado adelante ciertas decisiones, como es el caso de la oposición al proyecto Hidroaysén, o los múltiples conflictos por el agua a lo largo de todo el país.

\section{Equívocos de asumir una distinción fuerte entre ciencia y política}

Un elemento final es el posicionamiento que ha tomado el campo científico en Chile, pues sus actividades repercuten directamente en la construcción del tema "cambio climático", no solo desde sus hallazgos de evidencia, sino particularmente en su rol de personalidades públicas que comunican la ciencia hacia la sociedad a la que sirven y deben rendir cuentas como agentes receptores de financiamiento público.

La ciencia es política, pues realiza definiciones que son decisiones previas a la toma de decisión realizada por el mundo político, el cual responde a un modo de legitimación (electoral) que es más directo y comprensible que el de la ciencia (auto- 
ridad conferida por la comunidad científica) para la ciudadanía. Por ello cuando los científicos marcan la diferencia entre ciencia y política esta es una distinción más analítica que operativa y es fuente de equívocos, ya que posicionan a la ciencia desde un estatus alejado del quehacer de las personas, que son en definitiva quienes tomarán o no las acciones necesarias de mitigación y adaptación. Este posicionamiento de la ciencia también utiliza el encuadre "observar y esperar", de forma similar a la elite política y económica del país.

Así, dentro de un tema científico tan esencialmente político como el cambio climático (Boykoff y Yulsman, 2013) existe una oportunidad para que la ciencia desarrolle una auto-comprensión distinta de su rol, más proactiva en la exploración de oportunidades para influir en las agendas públicas y políticas, negociando sin cerrarse a comprender los procesos políticos y culturales cruciales para que su investigación se transforme en aplicaciones concretas para las personas, sean éstas políticos, empresarios, o ciudadanos comunes.

Este alejamiento de la política y la ciudadanía, y su pretensión de "pureza" , se basa en una ilusión de objetividad que busca construir la academia mediante un acto lingüístico profundamente ideológico y político. Luego de que Heisenberg enunciase el llamado principio de incertidumbre o indeterminación en 1925, ya no es posible hablar de objetividad sino más bien de intersubjetividad, en el sentido de que es la comunicación de los investigadores hacia: (a) la comunidad científica internacional y (b) la sociedad (nacional, global) la que otorga legitimidad al proceso de investigación, y no el acceso a una realidad que se presenta transparente, "tal cual es". Cuando los investigadores posicionan su trabajo desde la objetividad olvidan que el sentido del conocimiento no se encuentra fuera de sus condiciones sociohistóricas. Incluso en el desarrollo de "ciencia pura" intervienen paradigmas y preguntas que responden a condiciones de reflexividad históricamente condicionadas. Por esto, tan importante como producir las bases científicas es posibilitar su difusión e impacto social, especialmente en relación a las respuestas que las personas deben procesar y accionar para mitigar y adaptarse al cambio climático.

\section{Recomendaciones}

En primer lugar se manifiesta la necesidad de realizar una segmentación de la opinión pública chilena respecto a sus posiciones frente al cambio climático, ya que cada segmento posee un compromiso distinto, y en orden a mejorar la efectividad de la comunicación del tema es central su reconocimiento.
En segundo lugar, es relevante que la comunidad científica como integrante de la "corriente de políticas" conecte el cambio climático con el presente.

En tercer lugar, el uso de estructuras narrativas para influenciar las percepciones de riesgo y las preferencias de políticas individuales asociadas al cambio climático demuestra ser una poderosa herramienta (Jones, 2014), pues los seres humanos somos nuestras historias, y las historias deben narrarse (Marquard, 2001).

En cuarto lugar, el encuadre de salud humana muestra ser un buen motor para el cambio de comportamiento (Semenza et al. 2011). El conocimiento de amenazas a la salud (olas de calor, sequías, incendios) debería ser promovido en campañas de salud. Es importante constar que las poblaciones vulnerables de bajo estatus socioeconómico no responden tan bien como otras poblaciones a las campañas de salud, por lo que requieren otras aproximaciones complementarias (Semenza et al. 2011).

Finalmente es importante señalar que el grado de concentración de la propiedad de los medios de prensa en Chile es nociva para el desarrollo de la adaptación y la resiliencia al cambio climático. Este estudio de caso halló evidencia de servidumbre de los medios de comunicación hacia el Estado, posibilitada por la ausencia de cantidad y diversidad de voces y sensibilidades que puedan proyectar sus visiones hacia el espacio público, generando fricción, conflicto y debate, elementos catalizadores de dinámicas de innovación y apertura a las incertidumbres que están en la base de las sociedades democráticas actuales, y no una ilusión de convergencia discursiva que no reflexiona acerca de las causas cotidianas de fenómenos globales como el cambio climático, ni cuestiona las condiciones estructurales que permiten la vulnerabilidad socioeconómica, la cual está traslapada con la vulnerabilidad y exposición climática.

\section{Referencias}

Abbasi, D. R. (2006). Americans and climate change: closing the gap between science andaction. New Haven, CT: Yale School of Forestry and Environmental Studies.

Adger, W. N., Hulme, M., Lorenzoni, I., Naess, L. O., Wolf, J., Dessai, S., Goulden, M., y Wreford, A. (2009). Are there social limits to adaptation to climate change? Climatic Change. 93.

Aldunce, P. (2013). Framing resilience: practitioner's views of its meaning and usefulness in disaster risk management practice. Phd Thesis. 
Alley, K. (2012). Mass media roles in climate change mitigation. En Chen, W.-Y., editor, Handbook of Climate Change Mitigation. Springer Science Business Media.

Antilla, L. (2005). Climate of scepticism: US newspaper coverage of the science of climate change. Global Environmental Change Global Environmental Change, 15(4):338-352.

Ayers, J. M. y Huq, S. (2008). The value of linking mitigation and adaptation: a case study of bangladesh. Environmental Management, 43(5):75364 .

Backstrand, K. y Lovbrand, E. (2006). Planting trees to mitigate climate change: Contested discourses of ecological modernization, green governmentality and civic environmentalism. Global Environmental Politics, 6(1):50-75.

Bassett, T. J. y Fogelman, C. (2013). Deja vu or something new? the adaptation concept in the climate change literature. Geoforum, 48:42-53.

Baumgartner, F. R. y Jones, B. (1993). Agendas and instability in American politics. University of Chicago Press, Chicago.

Boykoff, M. T. y Boykoff, J. (2004). Balance as bias: global warming and the us prestige press. Global Environmental Change, 14(2):125-136.

Boykoff, M. T. y Yulsman, T. (2013). Political economy, media, and climate change: sinews of modern life. Wiley Interdisciplinary Reviews: Climate Change, 4(5):359-371.

Brown, K. (2011). Sustainable adaptation: An oxymoron? Climate and Development. 3, 1:21-31.

Cannon, T. y Muller-Mahn, D. (2010). Vulnerability, resilience and development discourses in context of climate change. Natural Hazards, 55(3):621-635.

Capstick, S. B. y Pidgeon, N. F. (2014). What is climate change scepticism? examination of the concept using a mixed methods study of the uk public. Global Environmental Change, 24:389-401.

Carter, N. (2014). The politics of climate change in the uk. Wiley Interdisciplinary Reviews, 5:423433 .

Chomsky, N. y Herman, E. S. (2009). Los Guardianes de la libertad: Propaganda, desinformación y consenso en los medios de comunicación de masas. Crítica, Barcelona.

Cobb, R. y Elder, C. (1972). Participation in American politics: The dynamics of agenda building. The John Hopkins University Press, Baltimore.
Crutzen, P. J. y Stoermer, E. (2000). The "anthropocene". Global Change Magazine, 41.

Dewulf, A. (2013). Contrasting frames in policy debates on climate change adaptation. Wiley Interdisciplinary Reviews: Climate Change, 4(4):321330 .

Downs, A. (1972). Up and down with ecology: the 'issue-attention' cycle. The Public Interest, 28.

Engels, A., Hutter, O., Schafer, M., y Held, H. (2013). Public climate-change skepticism, energy preferences and political participation. Global Environmental Change Global Environmental Change(2).

Entman, R. M. (1993). Framing: Toward clarification of a fractured paradigm. Journal of Communication, 43(4):51-58.

Fransen Taryn, H. J. (2011). GHG-Framed mitigation actions by developing countries.

Giddens, A. (2010). La política del cambio climático. Madrid.

Gordon, J., Deines, T., y Havice, J. (2010). Global warming coverage in the media: Trends in a mexico city newspaper. Science Communication, $32(2): 143-170$.

Hall, S. (2000). The social production of news. En Marris, P., editor, Media Studies. A reader. New York University Press.

Inglehart, R. (1990). Culture shift in advanced industrial society. Princeton University Press, New York.

IPCC (2007). Climate change 200\%: impacts, adaptation and vulnerability. Cambridge, UK; New York: Published for the Intergovernmental Panel on Climate Change [by] Cambridge University Press.

IPCC (2013). Climate change 2013: the physical science basis. Summary for Policymakers: Working Group I contribution to the IPCC fifth assessment report.

J., W. y C., M. S. (2011). Individual understandings, perceptions, and engagement with climate change: insights from in-depth studies across the world. WIREs Climate Change, 2:547-569.

Jones, M. D. (2014). Cultural characters and climate change: How heroes shape our perception of climate science. Social Science Quarterly, 95(1):1-39. 
Juhola, S., Keskitalo, E. C. H., y Westerhoff, L. (2011). Understanding the framings of climate change adaptation across multiple scales of governance in Europe. Environmental Politics, 20(4).

Kim, S. Y. y Wolinsky-Nahmias, Y. (2014). Crossnational public opinion on climate change: The effects of affluence and vulnerability. Global Environmental Politics, 14(1):79-106.

Kingdon, J. W. (1984). Agendas, alternatives, and public policies. Boston: Little, Brown.

Marquard, O. (2001). Filosofía de la compensación: Estudios sobre antropología filosófica. Barcelona, Paidós.

McCombs, M. y Ghanem, S. (2003). The convergence of agenda-setting and framing. En Reese, D., editor, Perspectives on Media and our understanding of the social world. Lawrence Erlbaum Associates, New Jersey.

Miller, C. A. (2000). The dynamics of framing environmental values and policy: four models of societal processes. Envirenmental Values, 9:211-233.

Ockwell, D., Whitmarsh, L., y O‘Neill, S. (2009). Reorienting climate change communication for effective mitigation. Science Communication, 30(3):305-327.

Olausson, U. (2009). Global warming-global responsibility? media frames of collective action and scientific certainty. Public Understanding of Science, 18(4):421-436.

Parker, C., Letelier, M., y Muñoz, J. (2013). Elites, climate change and agency in a developing society: the chilean case. Environment, Development and Sustainability, 15(5):1337-1363.

Poortinga, W., Spence, A., Whitmarsh, L., Capstick, S., y Pidgeon, N. F. (2011). Uncertain climate: An investigation into public scepticism about anthropogenic climate change. Global Environmental Change, 21(3):1015-1024.
Pralle, S. B. (2009). Agenda-setting and climate change. Environmental Politics, 18(5):781-799.

Rochefort, D. y Cobb, R. (2001). The politics of problem definition. University press of Kansas, Lawrence.

Somorin, O. A., Peach, H. C., Visseren-Hamakers, I. J., Sonwa, D. J., Arts, B., y Nkem, J. (2012). Congo basin forests in a changing climate: policy discourses on adaptation and mitigation $($ redd + ). Global Environmental Change, 22(1):288-298.

Sterman, J. D. (2011). Communicating climate change risks in a skeptical world. Climatic Change, 108(4):811-826.

Takahashi, B. y Meisner, M. (2013). Agenda setting and issue definition at the micro level: Giving climate change a voice in the peruvian congress. Latin American Policy, 4(2):340-357.

UNFPA-CEPAL-ECLAC (2001). Informe Regional de Población en América Latina y el Caribe 2011. Invertir en Juventud.

Uusi-Rauva, C. y Tienari, J. (2010). On the relative nature of adequate measures: Media representations of the eu energy and climate package. Global Environmental Change, pp. 492-501.

Van Dijk, T. A. (1999). El análisis crítico del discurso. Revista anthropos, 186:23-36.

Vicuña, S. (2012). Adaptation challenges for middle income countries: the experience of Chile. Centro de Cambio Global UC. Adaptation Futures. International Conference on Climate Adaptation, Tucson.

Whitmarsh, L. (2011). Scepticism and uncertainty about climate change: Dimensions, determinants and change over time. JGEC Global Environmental Change, 21(2):690-700.

Wodak, R., editor (2001). Methods of critical discourse analysis. SAGE Publications, London. 